4 norden 



\section{A better life for children and adolescents through diet and exercise}

Nordic catalogue of initiatives and best practice for improved health and quality of life via diet and physical activity 
A better life for children and adolescents through diet and exercise

Nordic catalogue of initiatives and best practice for improved health and quality of life via diet and physical activity

TemaNord 2009:501

(C) Nordic Council of Ministers, Copenhagen 2008

ISBN 978-92-893-1803-7

Print: Ekspressen Tryk \& Kopicenter

Copies: 200

Printed on environmentally friendly paper

This publication can be ordered on www.norden.org/order. Other Nordic publications are available at www.norden.org/publications

Printed in Denmark

Nordic Council of Ministers

Store Strandstræde 18

DK-1255 Copenhagen K

Phone (+45) 33960200

Fax (+45) 33960202

\section{Nordic Council}

Store Strandstræde 18

DK-1255 Copenhagen K

Phone (+45) 33960400

Fax (+45) 33111870

www.norden.org

\section{Nordic co-operation}

Nordic cooperation is one of the world's most extensive forms of regional collaboration, involving Denmark, Finland, Iceland, Norway, Sweden, and three autonomous areas: the Faroe Islands, Greenland, and Åland.

Nordic cooperation has firm traditions in politics, the economy, and culture. It plays an important rol in European and international collaboration, and aims at creating a strong Nordic community in a strong Europe.

Nordic cooperation seeks to safeguard Nordic and regional interests and principles in the global community. Common Nordic values help the region solidify its position as one of the world's most innovative and competitive. 


\section{Contents}

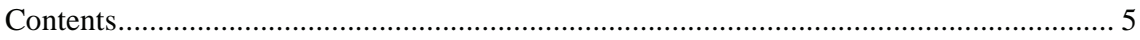

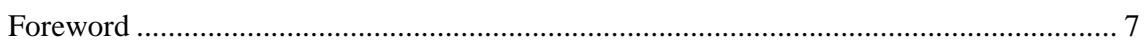

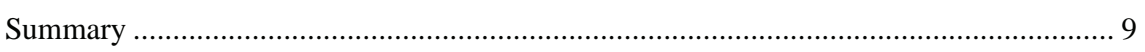

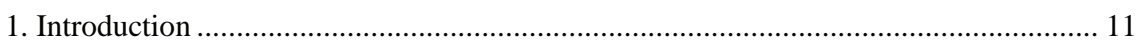

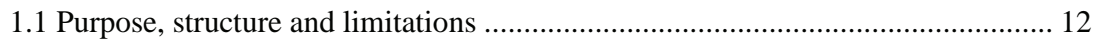

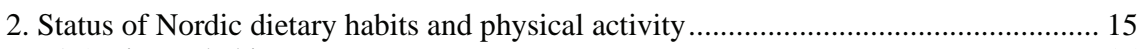

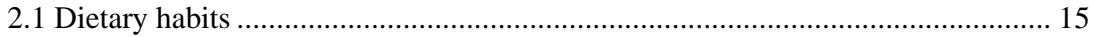

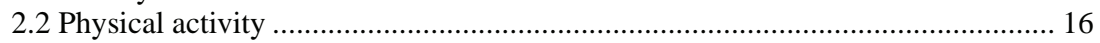

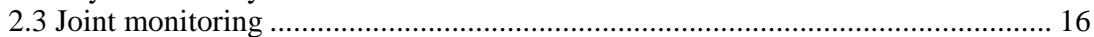

3. The Nordic Council of Ministers' goals and visions for better

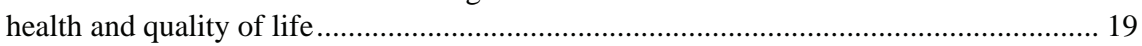

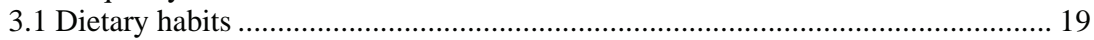

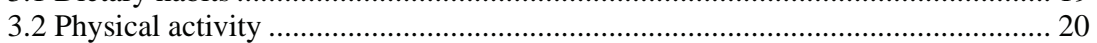

4. The authorities' opportunities to influence the diet and physical

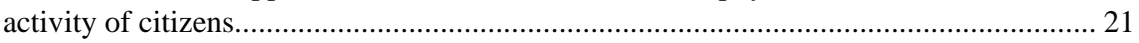

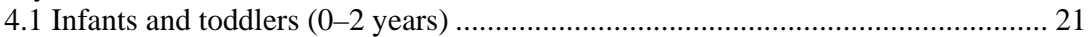

4.2 Pre-school children (3-6 years) ....................................................................... 21

4.3 School children (7-15 years) ……..................................................................... 22

5. Projects under the auspices of the Nordic Council of Ministers ................................... 25

6. Denmark's initiatives for the health of children and young people ............................... 29

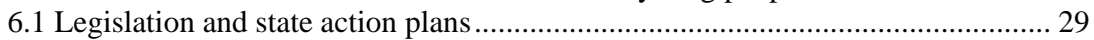

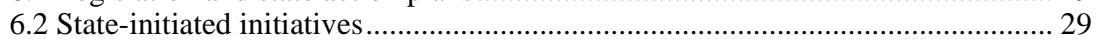

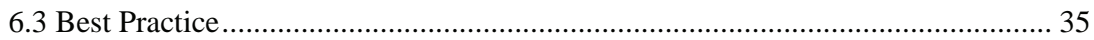

7. Norway's initiatives for the health of children and young people ................................ 39

7.1 Legislation and state action plans ........................................................................ 39

7.2 State-initiated initiatives for nutrition and physical activity (national level) ........ 40

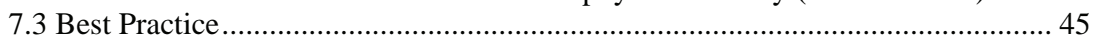

8. Sweden's initiatives for the health of children and young people.................................... 51

8.1 Legislation and action plans ............................................................................ 51

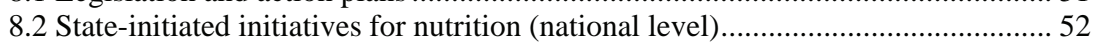

8.3 State-initiated initiatives for physical activity (national level) .............................. 53

8.4 Regional initiatives for physical activity .......................................................... 54

8.5 Regional initiatives for better dietary habits and physical activity ……................ 54

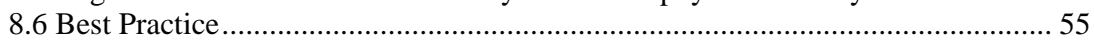

9. Finland's initiatives for the health of children and young people ................................. 57

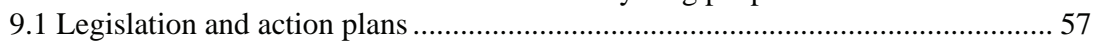

9.2 State-implemented initiatives for a healthier lifestyle ........................................ 58

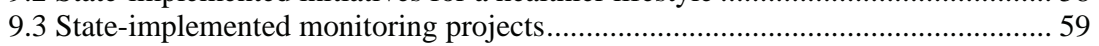

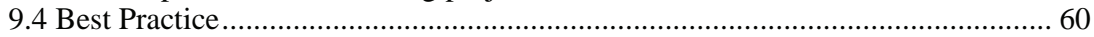

10. Iceland's initiatives for the health of children and young people ..............................6 63

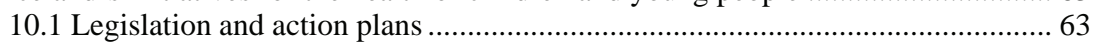

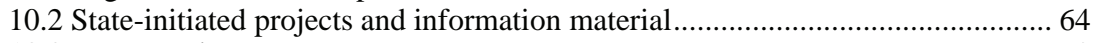

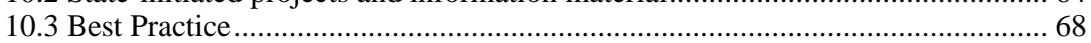


11. Health promotion through labelling and marketing of foodstuffs ............................... 71

11.1 The goals of the Nordic Council of Ministers ..................................................... 71

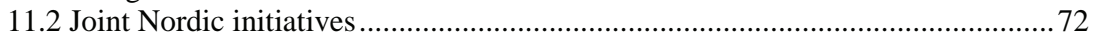

11.3 Danish initiatives on labelling and marketing ................................................. 72

11.4 Norwegian initiatives on labelling and marketing............................................... 74

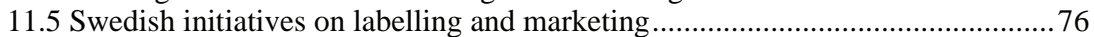

11.6 Finnish initiatives on labelling and marketing ................................................. 77

11.7 Icelandic initiatives on labelling and marketing................................................. 78

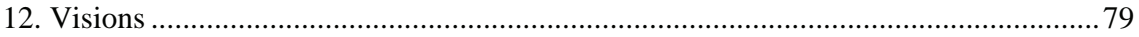

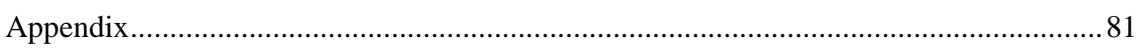

Table overview of each country’s initiatives listed by topic ........................................ 81 


\section{Foreword}

This first catalogue is a follow-up report to the Nordisk Handlingsplan for bedre sundhed og livskvalitet gennem mad og motion, (Nordic Plan of Action on better health and quality of life through diet and physical activity) and is the result of a co-operation between all five Nordic countries. The Nordic reference group is comprised of:

- Anita Andaas Aadland, physical activity in Norway

- Anne Kathrine O. Aarum, nutrition in Norway

- Elisabet Hay, physical activity and nutrition in Sweden

- Erlingur Jyhannsson, physical activity in Iceland

- Holmfridur Thorgeirsdottir, nutrition in Iceland

- Mari Miettinen, physical activity in Finland

- Raija Kara, nutrition in Finland

The catalogue was compiled and written by Puk Maia Ingemann Holm, of the Danish Veterinary and Food Administration, who is one of the representatives in the reference group together with Senior Advisor Bente Stærk. 



\section{Summary}

As the follow up report to the Nordic Action Plan on better health and quality of life through diet and physical activity (Nordisk Handlingsplan for bedre sundhed og livskvalitet gennem mad og motion), this document gather the initiatives for better health for children and youth in the Nordic countries.

Efforts are being made within wide areas in all the Nordic countries to improve the quality of life of their citizens using health-promoting means. Areas of focus are diet and physical activity, including differing age groups, vulnerable groups, marketing of unhealthy foods to children, but also the working environment, accidents and much more. These are all factors that impact on people's health and thus their quality of life.

Each country has an Action Plan for better health. These define certain goals to be achieved within given timeframes. One of the goals is to increase the levels of physical activity and the intake of healthy foods. All the countries are focussing in particular on children and young people. Therefore this catalogue is limited to initiatives for this group.

To a great extent, the Nordic countries promote health in differing ways. In Sweden, Norway and Iceland, concrete initiatives are implemented at the municipal level based on state-defined frameworks. In Finland, the municipalities, NGOs and associations are the primary players in the health-promoting efforts. And in Denmark, health promoting efforts involve many partnerships that are initiated by the state in collaboration with interest organisations and industry.

Best Practice is supported by a foundation of diverse initiatives implemented in the different countries. Some of these initiatives other than Best Practice have therefore been briefly outlined in the catalogue as inspiring reading.

Denmark has selected three Best Practice projects. The first is a cooperation called Alt om kost (Diet in a nutshell - a taste for life) by the Danish Veterinary and Food Administration. The project gathers data and information on diet and health and is accessible over the internet. The second is GetMoving, an annual campaign from the Danish National Board of Health, the aim of which is to inspire children and young people to move more, and last but not least, 6 om dagen (6 a-day), a partnership between industry and the Danish Veterinary and Food Administration that promotes adult Danes to eat 6 and children to eat 4 pieces of fruit and vegetables daily.

Sweden has selected three Best Practice projects. The first is $\mathrm{Be}$ spisning i børnehaver og skoler (Eating in nursery schools and schools), which offers free breakfasts in nurseries and schools. Second is Øget 
fysisk aktivitet i skolen (Increased physical activity in schools). An amendment to the mandatory pedagogic school plan was introduced in 2003, stating that the schools must endeavour to offer all pupils daily physical activity throughout the school day. The third project, Retningslinier for måltider i børnehaver og skoler (Guidelines for meals in nurseries and schools) defines guidelines for the food that is served in schools, institutions and after-school clubs.

Finland has selected two Best Practice projects. The first is DEHKO (The National Diabetes Programme), which is managed by the Finnish Heart Foundation. This focuses on the diabetes problem, and its relationship to risk factors such as overweight, and on early initiatives towards young people. This includes FIN-D2D the purpose of which is to implement the programme. Another example of Best Practice in Finland is HEPA (Health-Enhancing Physical Activity). This project focuses on promoting physical activity in the population using cross-sector cooperation.

Norway has selected three Best Practice projects. The first is Fysisk aktivitet og måltider i skolen (Physical activity and meals in schools). The main purpose of this project is to develop models in which one hours' daily physical exercise and good frameworks for healthy meals are integrated into the school day. The second is Skolefrugt (School Fruit) in which some of Norway's schools are able to offer pupils fruit and vegetables during school time. The third is Aktive barn (Active children). This project is intended to promote physical activity as a transport option.

Iceland has selected the major health project Everything affects us especially ourselves!. This is a collaboration project between the Public Health Institute of Iceland and more than 20 municipalities. The purpose of this project is to improve the lifestyle of children and young people, and their families. 


\section{Introduction}

The world's population is getting too heavy! WHO warns that the rising prevalence of obesity threatens both the public health and social economics in Europe. Today, half the population of Europe and every fifth child are overweight. A new analysis from WHO reveals that treatment of overweight and obesity consumes about $6 \%$ of health sector costs. WHO calls the figures alarming, and states that if the countries do not act now, 150 million people in Europe will be overweight by $2010^{1}$.

At a conference in Istanbul in November 2006, the European Ministers of Health agreed on a joint declaration against the European obesity epidemic. WHO also recommended that countries draw up national strategies and polices to promote healthy food and physical activity as well as prevention of overweight.

The situation in the Nordic countries is very similar to that seen in the rest of Europe: The number of overweight adults in the Nordic region is increasing, and is now at $40 \%$. Similarly, the number of overweight children in the Nordic region is increasing, and is now at $15-20 \%{ }^{2}$. Healthier eating habits and more physical activity are the most important tools to counteract the problem of overweight.

One of the supreme goals for the Nordic Council of Ministers is to ensure better health and quality of life on equal terms for all Nordic citizens. Considerable efforts are already underway in the Nordic region to try and meet this goal. We are moving towards joint efforts that can make a difference in the long term.

The joint Nordic Plan of action for better health and quality of life encourages initiatives in many areas. Joint Nordic monitoring of eating habits, physical activity and overweight provide the opportunity for ongoing assessment and comparison of the situation in each Nordic country. Access to comparable and valid data is a crucial pre-requisite if we are to follow up the joint Nordic goals.

Joint Nordic monitoring of eating habits, physical activity and overweight provide the opportunity to optimally assess the "Best Practice" in the initiatives in the area.

This catalogue is the start of this work. Where does each and every one of us stand? The catalogue provides a good foundation for further discussion and for drawing up what in the future will constitute "Best practice" in the Nordic region.

\footnotetext{
${ }^{1}$ Press release from the Nordic Council of Ministers 16 Nov. 2006 "European Obesity Summit in Istanbul”

2 "Et bedre liv gennem mad og motion", (A better life through food and motion) the Nordic Action Plan on better health and quality of life through food and physical activity. 2006. S. 5.
} 
Even though the individual bears a great deal of the responsibility for their choice of lifestyle, the promotion of healthy eating habits and physical activity, and prevention of overweight, is a collective responsibility. This multi-sector access is essential to generate results within this area. Therefore, this catalogue is addressed to a wide audience: municipalities, relevant government departments, organisations and associations with an interest in prophylactic work.

\subsection{Purpose, structure and limitations}

\subsubsection{The purpose of the catalogue}

The primary purpose of this catalogue is to collect the ongoing stateinitiated or completed initiatives that promote better health and quality of life through diet and physical activity in the Nordic countries.

The intention is to update the catalogue every second year. Continuous updates will enable the catalogue to be used as a tool to generate an overview of whether the joint goals for development of eating habits, physical activity and overweight in the Nordic countries are being achieved.

The Nordic Council of Ministers ${ }^{3}$ has previously formulated the goals in the Plan of action for better health and quality of life that focuses on securing:

- A clear improvement in the diet of Nordic citizens.

- A large majority of adult and older citizens meeting the recommendations on physical activity, and that all children are active.

- Success in reducing the number of overweight and obese citizens in the Nordic region, particularly among children and young people.

- A low tolerance to social inequality with respect to health that can be linked to diet and physical activity.

The action plan contains the following prioritised areas and target groups for the Nordic cooperation:

- Children and young people must have the pre-requisites to make healthy choices and must not be exposed to environments that encourage unhealthy choices.

- Healthy choices must be made easier for everybody.

- Initiatives must target vulnerable groups.

\footnotetext{
${ }^{3}$ Refers in the Action Plan to Ministers for Fisheries and Aquaculture, Agriculture, food and Forestry and to the Ministers of Health and Social Affairs.
} 


\subsubsection{The structure of the catalogue}

The present catalogue of projects has gathered two to three state-initiated projects from each of the Nordic countries, which were assessed to be the countries' "Best Practice"

Because a variety of methods are used and the responsibility distribution between the political decision-taking levels varies between the countries, there will be substantial differences in the methods behind the projects which thus cannot be compared directly, but should be used as a source of inspiration. Thus the catalogue is primarily intended to provide examples of successful projects aimed at differing target groups (age, social groups, etc.), and the organisational aspects can be omitted unless the reader is specifically interested in them. An overview of the projects is presented at the rear of the catalogue grouped according to action area/prevention environment.

Because individual "Best Practice" cannot illustrate an overall picture of the efforts in the area, the catalogue also contains a brief description of other initiatives that support each country's "Best Practice".

And, finally, the catalogue contains a section on the relevant regulations and guidelines governing labelling and marketing in each Nordic country. These areas are highlighted in the Nordic Plan of action for better health and quality of life as areas in which the Nordic countries should collaborate in order to influence the efforts in the EU. During 2007, several initiatives have been implemented to strengthen the Nordic cooperation and coordination within the areas.

\subsubsection{Delineating the target groups for the projects in the catalogue}

The present catalogue has been limited to describe initiatives for children and young people. There is agreement between WHO, the EU, the Nordic region and each Nordic country that the increasing prevalence of overweight and lifestyle disease in children and young people is particularly disturbing. It is in childhood that the foundations of healthy habits are laid, and children and young people are thus highly interesting from a prophylactic perspective.

The Nordic Plan of action for better health and quality of life emphasises that day care facilities, schools and sports associations play an important role in the efforts to promote healthy habits in children. It is important that the quality and the scope of options in day institutions, schools and sports associations are sufficient in relation to the need. Initiatives thus have to be implemented locally in the community as well as at a national level.

An appendix at the rear of the catalogue presents an overview of the Nordic countries' efforts in promoting children and young people's 
physical activity and healthier diet. You will also find references to supplementary reading on each initiative. 


\section{Status of Nordic dietary habits and physical activity}

Healthier dietary habits and increased physical activity are the most important tools to counteract the problem of overweight.

\subsection{Dietary habits}

The intake of fruit and vegetables in the Nordic population is considerably lower than that recommended. Studies show that fruit and vegetables have a beneficial effect on the prevention of development of lifestyle diseases ${ }^{4}$.

The average intake of added sugar for children in the Nordic region exceeds the recommended limits. Intake of added sugar is important not least in the development of overweight and obesity. The action plan clearly stipulates that the Nordic countries will continue their efforts to limit the availability and intake of sugar-sweetened drinks and snacks in schools, day care facilities and other places where children spend time.

Intake of dietary fibre is too low compared to the recommendations. Dietary fibre has a relatively low glycemic index, is good for movement through the gastro-intestinal tract, and is believed to reduce the risk of cancer of the colon ${ }^{5}$. Therefore intake of fibre-rich bread and grain products must be promoted.

Furthermore, the intake of fish by Nordic children and young people is lower than recommended. Fish contains the long-chain unsaturated fatty acids (omega-3 fatty acids), vitamin D, iodine and selenium. Eating the recommended amounts of fish reduces the risk for cardiovascular diseases. Lack of vitamin D can cause loss of bone tissue, which can increase the risk of osteoporosis in old age. Lack of iodine can cause impaired thyroid function and consequent risk of disturbances in metabolism. Furthermore, it is possible that selenium-rich food can reduce the risk for certain types of cancer ${ }^{6}$

\footnotetext{
${ }^{4}$ Danmarks Fødevareforskning „Forslag til retningslinier for sund kost i skoler og institutioner, rapport 2005. S. 22 (Ovesen et al, 2002) (The Danish National Food Research Institute ”Proposed guidelines for healthy food in schools and institutions, Report 2005, p. 22 )

5 "Energy-releasing substances and dietary fibre". The Directorate of Food, 1999

6 „Tips om fisk“, Fødevarestyrelsen, 2005, 1. udgave 2. oplag. Form og Co. (Tips on fish, The National Veterinary and Food Administration, 2005, $1^{\text {st }}$ edition, $2^{\text {nd }}$ printing Form and Co.)
} 


\subsection{Physical activity}

In general, people in the Nordic region exercise too little. This also applies to children. At the same time, there is a tendency to polarisation as shown by the fact that the group of physically active people is becoming more physically active, and the group of inactive people is growing. There is also a trend that children get less active the older they get. This has been observed in Nordic studies where almost two-thirds of young people are physically inactive ${ }^{7}$.

Physical activity helps prevent lifestyle and population diseases including muscle and skeletal conditions, certain types of cancer, stress, psychological conditions and osteoporosis. In addition, physical activity prevents cardiovascular diseases, elevated cholesterol and blood pressure, overweight, obesity, insulin resistance and type 2 diabetes $^{8}$.

Studies in Norway, Sweden, Denmark and the USA have documented that children that are physically active have greater enjoyment of life and self-confidence, have good general health, feel less helpless, are less tired in the morning, find it easier to make friends and feel less excluded ${ }^{9}$.

\subsection{Joint monitoring}

The present catalogue is one of the steps to create closer co-operation on methods to assess the development of the individual initiatives to promote healthier dietary habits, physical activity and prevalence of obesity. A common Nordic understanding of the monitoring methodology will ensure that the Nordic countries use common methods. This means that there will be a common comparison basis for measuring the efficacy of initiatives across borders.

In other words, a common monitoring process is essential for the quality of the continued Nordic "Best Practice" cooperation. It has already been decided to start a Nordic project which will develop and validate a joint, cost-effective Nordic monitoring system. Joint monitoring will be applied in three main areas:

- Dietary habits Is currently conducted every 3 to 10 years, which is far too infrequently in relation to the rapid developments in the

\footnotetext{
${ }^{7}$ Fysisk aktivitet og evidens. Livsstilssygdomme, folkesygdomme og risikofaktorer mv. Sundhedsstyrelsen, September 2006. (Physical activity and evidence. Lifestyle diseases, public diseases and risk factors, etc. The National Board of Health, September 2006) National HEPA-strategy and its implementation in Finland. Mari Miettinen, Senior Officer, Ministry of Social Affairs and Health, Finland. Handlingsplan for fysisk aktivitet 2005-2009 - Sammen for fysisk aktivitet, Norge. (Action Plan for Physical Activity 2005-2009 - Together for Physical Activity, Norway).

${ }^{8}$ Sundhedsstyrelsens hjemmeside „Hvorfor 30/60 minutter?“, den 16.03.2007 (The National Board of Health website "Why 30/60 minutes?” on 16.03.2007.

${ }^{9}$ Børn og bevægelse og Faktaark om fysisk aktivitet. Sundhedsstyrelsen, 2005. (Children and Movement, and Facts sheet on physical activity The National Board of Health. 2005)
} 
area. At the same time there are vast differences in methodology in the Nordic countries' studies (year and frequency of collection, age ranges, etc.).

- Physical activity The scope of existing data collections is very limited compared to the dietary area, and neither can they be compared over time nor between countries.

- Prevalence of overweight and obesity The frequency and comparability of existing Nordic data on BMI and waist/hip ratio is not sufficient to enable continuous monitoring of overweight.

Joint monitoring will enable us to collect data on adults, young people and children. This can provide a picture of how well we are achieving the goals set for developing the population's dietary habits and levels of physical activity, and on the prevalence of overweight. 



\section{The Nordic Council of Ministers' goals and visions for better health and quality of life}

In 2006, the Nordic Action Plan for better health and quality of life defined goals and visions for the developments in overweight:

Goal 2011:

The rise in the number of overweight and obese citizens should have stagnated or started to fall.

Vision 2021:

- The number of overweight or obese adults shall have fallen by $30 \%$ compared to the present level

- The number of overweight or obese children and young people shall have fallen by $50 \%$ compared to the present level

The goal and vision for developments in overweight must be converted into concrete results through the acquisition of new dietary and physical activity habits by the population.

\subsection{Dietary habits}

In accordance with the Nordic Action Plan for better health and quality of life, there must be a general, distinct improvement in dietary habits of the Nordic populations.

\section{Goal 2011:}

The intake of fruit and vegetables and whole grain products must be increased. The intake of fat, particularly saturated fat and trans fatty acids, as well as added sugar, must be reduced. The salt intake must fall or remain unchanged depending on the recommended national levels.

Vision 2021:

The majority of the populations eat in accordance with the Nordic Nutrition Recommendations (NNR). The current references for the vision are:

- At least $70 \%$ of the population above 10 years of age eat a minimum of $500 \mathrm{~g}$ fruit and vegetables daily. The average intake for children aged between 4 and 10 years is at least $400 \mathrm{~g}$ daily.

- The populations' average foodstuff intake complies with the NNR with regard to fats, saturated fats and trans fatty acids (max. $30 \mathrm{E} \%$ (percentage of total energy intake) in total, of which maximum $1 / 3$ is saturated fat, and at 
least $70 \%$ of the population complies with the NNR for fat intake (E\% between 25 and 35)

- $80 \%$ or more comply with the NNR with regard to the maximum daily intake of added sugar (max. $10 \mathrm{E} \%$ )

- $\quad 70 \%$ or more eat fish or fish products equivalent to a main meal twice a week

- At least $70 \%$ of the adult population has a daily intake of whole grain products which constitutes at least half of their total intake of bread and cereals

- The population's average intake of salt complies with the NNR.

\subsection{Physical activity}

In accordance with the Nordic Action Plan for better health and quality of life, the large majority of the adult population must follow the recommendations for physical activity, while all children must be physically active:

Goal 2011:

The current trend, in which an increasing number of adults and children are physically inactive, has stagnated or the numbers have fallen

Vision 2021:

- At least $75 \%$ of the adult population shall be physically active (moderate intensity) for at least 30 minutes every day

- All children aged 1-12 and at least 85\% of children and young people aged 12-16 are physically active (moderate intensity) for at least 60 minutes every day.

These recommendations apply to both adults and children unless otherwise stated, as is children's intake of fruit and vegetables and the amount of daily physical activity. 


\section{The authorities' opportunities to influence the diet and physical activity of citizens}

\subsection{Infants and toddlers ( $0-2$ years)}

The authorities' opportunities to influence infants and small children are via initiatives directed at the parents. Parents have a large responsibility to ensure that their children lead a physically active life and that they eat healthy food. While children are small, the healthcare nurses and GPs act as the primary advisors to parents. Good information materials and the provision of practical advice to parents on the importance of healthy food and physical activity for infants and small children can help to prevent overweight.

Breast milk is an important source of nutrition for infants. Breast milk strengthens the infant's immune system, and contains the correct nutrients for the child's age. The authorities can be involved in promoting breastfeeding by providing information and knowledge-based advice.

There are large differences between countries, day care facilities and nurseries with regard to the number of meals children are offered, the guidelines on provision of food, and the frameworks defining children's physical activity. There are also differences from family to family as to when children start in day care. For children who are looked after in day care or nurseries, the authorities can provide recommendations and guidelines for the meals and set requirements for the food offered and the framework for children's physical activity.

\subsection{Pre-school children (3-6 years)}

As the child grows up, the parents still have the primary responsibility for their children's dietary habits and levels of physical activity. They also know that by living a healthy life and being physically active they can be good role models. The authorities still have opportunities to provide advice on dietary habits and physical activity, and to inform parents of the importance of healthy food and physical activity through information campaigns and state offers that promote health. The physical environment should allow the child to be physically active all year round. This can occur by providing good opportunities for cycling, challenging park areas 
for physical activity, sports halls and requirements defining the offer and scope of physical activities in leisure time.

As in the nurseries and day care, the authorities have opportunity to influence children's eating habits and amount of physical activity during their time in nursery schools. This can be done by providing guidelines for the meals and by setting requirements for the food offered by day care facilities and for the framework for children's physical activity.

There is inter-country variation and inter-nursery school variation as to how much food children eat in nursery schools and whether the nursery school provides the food. In some countries, the children normally take packed lunches from home. In other countries, the day care facilities prepare lunch, snacks and sometimes even breakfast. The authorities have the possibility of affecting health directly through setting requirements on what children eat while they are in nursery school. A common factor in Nordic countries is the provision of 1-2 snacks during the day in many day care facilities, which provides a good opportunity to contribute to the child's intake of fruit and vegetables and to reduce the intake of added sugar.

Regardless of whether the children take food from home or whether it is prepared by the day care facilities, the authorities have the possibility to provide guidelines and set requirements ensuring that the nursery schools draw up a food and mealtime policy through which parents and personnel decide which foods children can/cannot eat, and how and whether children are involved in preparing the food.

\subsection{School children (7-15 years)}

The Nordic countries vary with regard to providing food and snacks in schools. In Norway and Denmark, children take a packed lunch from home, but some schools provide food in canteens. Sweden and Finland have a nationwide offer of free school lunches. Most Icelandic municipalities offer lunch in schools, which, in most cases, is subsidised by the municipalities.

Schools generally have fewer adults to supervise the physical framework around children's meals. But, as in the nursery schools, nurseries and day care facilities, the authorities can set requirements for the food offered by the schools and after-school facilities. The schools can similarly draw up food and mealtime policies, which set requirements for the packed lunches.

Physical activity can be promoted by setting requirements for environments around the schools, which make it safer to cycle or walk to and from school. Furthermore, the schools and after-school facilities can be required to draw up movement policies within the frameworks and offers for physical activity. Several studies have shown that children learn better 
and are more positive if they eat healthy food and are physically active during the day ${ }^{10}$

This catalogue looks in detail at the initiatives that have been implemented in the Nordic region and in each Nordic country of relevance to the Nordic action plan for children and young people. It is however important to emphasise that promoting healthy dietary habits in children and young people involves all aspects of a child's life and all influences on that child. This applies in particular to personnel in day care facilities and schools and, not least, to the parents. Easy-to-understand labelling and health-promoting marketing are important tools. These topics are discussed in Section 11.

${ }^{10}$ Børn og bevægelse. Sundhedsstyrelsen, 2005. (Children and Movement, The Danish Board of Health, 2005) 



\section{Projects under the auspices of the Nordic Council of Ministers}

The Nordic countries have a long tradition of co-operation within foodstuffs, health and nutrition. Since 1982, the Nordic countries have drawn up joint nutrition recommendations that comprise the scientific basis for each country's official dietary advice ${ }^{11}$. Nutrition recommendations also form the basis of the goals and visions in the Nordic Plan of Action on better health and quality of life.

In addition to the areas of cooperation mentioned in the Nordic Action Plan, the following Nordic projects on healthy habits for children and young people can be highlighted:

- Children, Food Consumption and Culture in Nordic Countries, held 2 workshops to establish a research group that represents research within food, nutrition and children in the Nordic countries. A first seminar Vegetables or sweets? Cultural perspectives on Nordic children's diet was held 15-16 March 2006 at the Centre for Consumer Science in Gothenburg. A second seminar was held at the beginning of 2007 in Trondheim. The project was concluded at the end of February 2007.

- Föreningen för familjecentrale, (Association of Family Centres,) Sweden: Nordisk ljus - et samarbetsprojekt om barn och barnfamiljers hälsa (Nordic Light - a collaboration project on the health of children and families with children). The project's goal is to create a Nordic idea forum and network for the various professions that work on a day-to-day basis with health promotion and prevention in families with children. The documentation for the project will be available on the organisation's website www.familjecentraler.se, and the results will be distributed by the Nordiska Högskolan för Folkhälsovetenskap (NHV) (Nordic School of Public Health).

- NOVA, Norway: Levekårsforskning med barneperspektiv (Research into living conditions from a child's perspective). The purpose of this project is to analyse the living conditions of children and young people, and conditions for socialisation. Conditions for socialisation are defined as the opportunities children and young people have to qualify for adult life. A central aspect of the work is to develop theories and indicators that can identify those living conditions of

${ }^{11}$ The most recent report "Nordic Nutrition Recommendations 2004 - Integrating nutrition and physical activity“, was published in March 2005 
children and young people that can be used comparatively in the Nordic region by both policy makers and researchers.

- Directorate of Health and Social Affairs: Nordisk Miljømedicinsk arbeidsgruppe (Nordic Environmental Medicine Working Group). The purpose of the Nordic Environmental Medicine Working Group is to promote and qualify the countries' efforts with national activities relating to the health and environments of children. The Working Group is to follow up the Ministerial decision in WHO, June 2004, by which the Nordic countries pledged, as did the other countries in the WHO Europe region, to draw up an Action plan for children's environment and health. The project is anchored in the Nordic countries' national health authorities. There is an international link to the WHO CEHAPE Task Force.

- The Norwegian Directorate of Health: Pilotprosjekt om metoder for medvirkning og involvering av barn og unge, (Pilot project on methods for influencing and involving children and young people) follow up of the $4^{\text {th }}$ WHO Ministerial Conference on the Environment and Health. In 2005, NMR established a Samarbejdsgruppe for miljømedicin (Cooperation Group on Environmental Medicine) that is following up the $4^{\text {th }}$ WHO Ministerial Conference on the Environment and Health in Budapest 2004. Their work is to develop national action plans for children's environment and health. A report from the conference in March 2006 is available: Report on a Youth Workshop on Youth Participation and Involvement Concerning Children and Youth's Environment and Health.

- NOVA, Norway: Nordisk konferanse om fattigdom og levekår for barn i de nordiske landene (Nordic Conference on Poverty and Living Conditions for Children in the Nordic Countries). Norway (BLD) will arrange a Nordic conference on poverty and children to highlight the problems from a Nordic perspective. The conference will take place in cooperation with relevant research environments in Norway that hold knowledge on poverty and children (FAFO/NOVA). There are similarities in the public system within the Nordic countries, and the Nordic region is concerned with how we can fight poverty in a constructive and sustainable manner.

- One proposal is to develop a common Nordic tool (guidelines) for schools/day care facilities that can be used to define their policies with respect to offers of food and drink in schools. Collaboration with organisations such as Skole og Samfund i Danmark (School and Society in Denmark)

- Swedish consumers in the collaboration: Sockerjakten (Hunt the Sugar) The Hunt the Sugar project is intended to involve and focus children on the increasing intake of sugar and the negative consequences of too much sugar in the daily diet. At the same time, the project will give children the background to enable them to 
critically view commercials for products that have a high sugar content. The goal is to get children and young people to be inquisitive and to influence them to eat more healthily.

- COPE - Children, Outdoor, Participation, Environment (NFK). The Nature, Open Air \& Cultural Environment Working Group has involved 42 schools in nine countries in the project that focuses on children's health combined with open air activities and a good local environment. The project will be concluded in 2007, and will provide input to WHO and EU work with the environment and health. A midway evaluation of the project was held in September 2006 at which it was concluded that implementation of the project was well advanced in many areas, and certain key areas were stressed.

The Nordic Council of Ministers focuses particularly on stopping the rise in the number of overweight and obese children and young people. The Action Plan on Better Health and Quality of Life, stipulates that the means to reverse this development must enable children and young people to make healthy choices and protect them from environments that encourage unhealthy choices. 



\section{Denmark's initiatives for the health of children and young people}

\subsection{Legislation and state action plans}

One of the purposes of the Danish Food Act ${ }^{12}$ is to promote healthy dietary habits. The Ministry for Family and Consumer Affairs has the task of disseminating information to the consumer on conditions that are governed by the law, including nutrition. The Ministry can also provide advice on and determine regulations for provision of public food. No initiatives have been taken to define regulations on requirements for food for children and young people, but several recommendations have been issued, c.f. below.

The national goals and strategies for public health 2002-10 are stipulated in Sund hele livet (Healthy throughout life), which was issued by the government in September $2002^{13}$. This health programme was detailed with respect to children and young people in Bedre sundhed for børn og unge (Better health for children and young people) November $2003^{14}$, which was an idea with several concrete initiatives for promoting healthier habits in children.

\subsection{State-initiated initiatives}

\subsubsection{Report on Food Policy}

In November 2006, the government published a Fødevarepolitisk redegørelse ${ }^{15}$ (Report on Food Policy). The goal was to get children to eat healthy food and have a natural relationship to movement. It was emphasised that day care facilities and schools have a responsibility in realizing this goal, but that the primary responsibility lies with the parents.

\footnotetext{
${ }^{12}$ Lov nr. 526 af 24. juni 2005 om fødevarer §§ 1, 10 og 12. (The Danish Food Act no. 526 of 24 June 2005 sections 1, 10, and 12.

${ }^{13}$ Sund hele livet - de nationale mål og strategier for folkesundheden 2002-10, Regeringen. September 2002 (Healthy throughout life - the national goals and strategies for public health 2002-10)

${ }^{14}$ Bedre sundhed for børn og unge, Regeringen, November 2003 (Better health for children and young people)

15 „Fødevarepolitisk redegørelse - i et forbrugerperspektiv“. November 2006. Ministeriet for Familie- og Forbrugeranliggender (Report on Food Policy - from the consumer perspective November 2006, The Ministry of Family and Consumer Affairs)
} 
According to the report, general guidelines should be drawn up for the municipalities which will facilitate the work of each municipality in formulating a diet and motion policy for children and young people. The intention is to strengthen the advice about diet and motion provided to municipalities and municipal institutions

The government also wishes that "as far as possible in day care facilities and schools, children will be able to buy a healthy meal in the middle of the day" as an alternative to the packed lunch. The meal scheme would be financed by the parents.

\subsubsection{The Ministry of Family and Consumer Affairs}

Under the auspices of the Ministry of Family and Consumer Affairs, the Danish Veterinary and Food Administration is to influence citizens' attitudes to nutrition. This will be effectuated using information on healthy dietary habits. The Danish Veterinary and Food Administration recommends that children aged between 4 and 10 years should on average eat $400 \mathrm{~g}$ fruit and vegetables a day, and that the intake of sugar should be limited. Projects are being continuously implemented and inspirational material addressing nursery schools, schools and after-school facilities is being distributed.

The following relevant projects have been initiated by the Ministry of Family and Consumer Affairs:

- Nutrition symbols guide the consumer to products that one can either "eat most of", "eat less of", and "eat least of" in relation to the content of fat, saturated fat, sugar, salt, and dietary fibre and, in some cases, fruit and vegetables

- $\quad$ For more information, go to www.spismest.dk and www.forbrug.dk.

- Contact: Else Molander - otherwise refer to Section 13 for plans for joint Nordic nutrition symbols.

- BørneBoxen (Children's Box) is an initiative using play to inspire healthy habits in the daily life of nursery school children. Tips, ideas, inspiration and tools are provided for healthy suppers, child participation in food preparation, games that allow children physical activity, involvement of parents, etc. BørneBoxen is run jointly by a partnership of the Danish Veterinary and Food Administration, the Danish Meat Association, FDB, the Food Industry and Suhr's Videncenter (Suhr's Knowledge Center, University College of Nutrition and Health)).

- $\quad$ For more information, go to www.boerneboxen.dk. 


\section{- $\quad$ Contact: Tove Dam}

- The Danish Veterinary and Food Administration is involved in the partnership 6 a-day which offers schedules for fun, practical and green parties for 3-8 year olds on www.frugtfest.dk, and school fruit. 6 aday explains why fruit and vegetables are healthy and how to introduce fruit and vegetables into the daily diet easily.

- $\quad$ For more information, go to www.6omdagen.dk.

- $\quad$ Contact: Susanne Tøttenborg.

- Leg dig sund (Play for health) The Danish Veterinary and Food Administration has received funds to develop information material on healthy food and lifestyle for socially-vulnerable families with children from 1-6 years of age, including families of ethnic origin other than Danish. The information material must include tools that can help the families to promote and maintain a healthy diet and lifestyle. For example, consultation nurses could be used when advising families with children. The material is implemented January 2008.

- $\quad$ For more information, go to www.legdigsund.dk

- Contact: Maria Haukrogh.

- Mad i bevcegelse (Food in movement) is a project led by the Danish Cancer Society, in which the Danish Veterinary and Food Administration is also involved. The purpose of the project is to improve the range of food and the food culture within sporting activities. This can help improve diet within sports environments.

- $\quad$ For more information: www.mad-i-bevaegelse.dk

- Contact: Simon Rask, The Danish Cancer Society.

- DKK 2 billion was allocated from 2006-2010, to be used on projects for development of good practice with respect to diet, nutrition and physical activity offered in day care facilities. To support the institutions in prioritising the work with formulating a food and physical activity policy, the Ministry of Family and Consumer Affairs and the Ministry of Health and Internal Affairs have drawn up general Guidelines for the municipal authorities and decision-takers. This material is intended to spotlight the benefits to the municipality of prioritising the establishment of policies for diet and physical activity in the municipal facilities for children. In addition, the material will contain guidance on how the municipality can tackle the task. Finally, the material will spotlight the extensive material and advice on diet and 
physical activity that is already available, and which is directed at the municipalities and/or institutions. The work with this material was started in 2007, and is expected to be completed at the end of 2008.

\section{- $\quad$ Contact: Karen Eriksen.}

- Whole grain partnership The purpose of this project is to create a foundation for a generic campaign for whole grain in autumn 20072012. The campaign is intended to stimulate Danes to eat more whole grain products. The goals will be achieved by a partnership between the health care services and industry. The partnership will build on, and exchange experiences from, the 6 a-day collaboration. Industry and the health care services will jointly develop a campaign based on the new recommended amounts of whole grain. Finally, a programme will be developed for monitoring and evaluating the overall initiative.

\section{- $\quad$ Contact: Bente Stærk}

- In September and November 2007, Ernœringsanbefalinger til skolemadsleverandører og -producenter (Nutrition recommendations for school food suppliers and manufacturers) and Ernæeringsanvisninger til skoler der selv producerer skolemad (Nutritional requirements for schools that prepare school food themselves) were published. These include guidelines for the composition of meals in schools which are considered to be healthy, are a step towards healthy eating, or are unhealthy foods.

- $\quad$ For more information, go to www.altomkost.dk.

- Contact: Tove Vestergaard Lauritsen.

- On 1 November 2005, the Motion and Nutrition Council was appointed by the Minister of Family and Consumer Affairs to act in a professional capacity as an advisory body on nutrition and motion (the Danish Food Act $\S 13)^{16}$. The Council has appointed a working group on the prevention of overweight in children and young people. In May 2007, the working group submitted a proposal for a strategy for prevention of overweight among children and young people in Denmark. This proposal suggested that a central body should be established for prevention of overweight that has resources and responsibility for preventive measures including coordination of the various initiatives. It was also suggested that monitoring and screening systems should be established that made it possible to evaluates the various initiatives; that nationwide campaigns should be run against the intake of sugar and fat; that physical activity should be promoted;

\footnotetext{
${ }^{16}$ www.meraadet.dk
} 
and that all national institutions and schools should draw up diet and physical activity policies that ensure that access to fat and sugar-rich products is tightly regulated.

\subsubsection{The Ministry of the Interior and Health}

The Danish National Board of Health, under the auspices of the Ministry of the Interior and Health, works to influence the health attitudes of the citizens. This is effectuated by information on the prevention of disease through exercise and physical activity. Projects and campaigns are being continuously implemented, and inspirational material for nursery schools, schools and after-school facilities is distributed.

The following relevant projects have been initiated by the Ministry of the Interior and Health:

The project Fysisk aktivitet som indsatsområde (Physical activity as an investment area) provides suggestions as to what can be done at the private level, in partnerships and by the authorities to encourage physical activity in children.

- $\quad$ For more information, go to http://www.sst.dk/Forebyggelse/ Mad_og_motion/Overvaegt/Anbefalinger/Voksne_generelt/ Fysisk_aktivitet.aspx?lang=da

- The Danish Board of Health is running one project called 60 minutter (60 minutes) (children and young people 2006), in which an information campaign, GetMoving, was run in week 36 in 2006, to make people aware that children should be active at least 60 minutes a day, and preferably more. GetMoving is described in more detail under Denmark's Best Practice. In 2007, inspiration material that incorporated theory and practice (cases) was prepared that describes how a municipality, day care facility and/or school can get started with drawing up a motion policy.

- For more information, go to http://www.sst.dk/Forebyggelse/ Mad_og_motion/Fysisk_aktivitet/Kampagner_og_projekter/ 60_minutter_2006.aspx

- Krop skal der til (Bodies are needed) is an educational programme on food and physical exercise for 3rd and 4th years.

- For more information, go to http://www.sst.dk/Forebyggelse/ Mad_og_motion/Fysisk_aktivitet/Kampagner_og_projekter/ Krop_skal_der_til.aspx 
- The Danish Board of Health has prepared material and checklists for several areas that day care facilities and schools should be focussed on, including Sundhedstegnet (Healthy!) The purpose is to stimulate day care facilities and schools to work with differing aspects of children's health - including healthy food and exercise. A materials box has been prepared which contains an inspiration catalogue, Healthy! newsletter, a frame for the Healthy! diploma and a link to www.sundhedstegnet.dk.

- Gang i Danmark (Get going in Denmark) is a campaign that puts the spotlight on physical activity in 2007. The campaign is funded by the Ministry of Health and the Interior and TrygFonden.

- $\quad$ For more information, go to www.gangidanmark.dk.

- In connection with the new school year in autumn 2007, the government will implement a nationwide campaign for fruit in schools. The campaign will draw attention to the fact that it is healthy to eat fruit.

\subsubsection{The Danish Ministry of Education}

Sport is an obligatory subject for all years in schools, with two lessons a week. It is however optional as to whether individual schools offer more sports lessons. The Danish Ministry of Education has published an inspirational brochure for school principals that describe how they can place healthy food and physical activity on the agenda and within the framework of the schools operations. The brochure covers three main issues:

- Why is it important that schools are concerned with food and physical activity?

- How can the schools become involved in these issues and make them an integrated part of the school's tasks?

- Which functions and roles can, and should, a school principal play in this context.

- $\quad$ For more information, go to http://pub.uvm.dk/2004/sundmad/kap02.html, which is a direct link to the Danish Ministry of Education's net publications.

\subsubsection{The Danish Ministry of Culture}

The Danish Ministry of Culture is also participating in the promotion of exercise by the development of sports activities. 
- The Danish Ministry of Culture supports a project in which Dansk Skoleidræt (Danish School Sports) and the National Olympic Committee and Sports Confederation of Denmark have joined forces to establish school sports associations at 60 schools in the country distributed between 20 municipalities. The purpose is to give all children the opportunity of more sports and physical activity in daily life.

- $\quad$ For more information, go to www.skoleidraet.dk.

- The Danish Ministry of Culture has a development fund Børn og unge $i$ bevcegelse (Children and young people in motion) of DKK 24 million distributed over three years which supports a variety of local projects. The projects focus on making it easier for children and young people to choose sports - in their local community and at times of the day when it suits them. The projects also aim at developing new dimensions and strengthening the quality of children's and young people's sporting activities.

- $\quad$ For more information, go to www.kulturministeriet.dk.

- Contact: Rosa Cedermark.

\subsection{Best Practice}

\subsubsection{Alt om Kost (Diet in a nutshell - a taste for life)}

In 2002, the project Alt om Kost - smag for livet (Diet in a nutshell - a taste for life) was launched by the Danish Veterinary and Food Administration. In partnership with other administrations, research institutions, and interest organisations, projects under Diet in a nutshell have been launched that promote health and reliable nutrition information for children, adults and the elderly. Diet in a nutshell has its own website under the Danish Veterinary and Food Administration which provides information and inspiration for healthy food.

Diet in a nutshell offers a "flying squad" that travels to all regions of the country to hold lectures about health free of charge. Members of the flying squad travel to municipalities, day care facilities and schools that want to work with food and food policies, and provide advice on what a food and meal policy entails. The flying squad has its own website on www.altomkost.dk and a telephone hotline.

The goals of Diet in a nutshell - a taste for life are to:

- promote healthy and good food and meals in schools and day care centres and thus influence children's dietary habits 
- strengthen information on healthy food to all citizens so that it is easier for each person to search for usable and reliable information among the vast amounts of data available.

- collect and continuously update nutrition information

- undergird the work of the flying squad when establishing food schemes, etc.

Diet in a nutshell is also responsible for publishing recommendations and inspirational materials on healthy food to day care facilities, schools, after-school schemes and clubs. Methods are designed to disseminate dietary advice and recommendations to the general public. The website contains recipes for healthy dishes prepared by enthusiastic chefs. Cookery books are also available. In 2007, work is ongoing on:

- spreading familiarity with the nutritional compass, which presents the 8 nutritional principles. In particular, there is focus on limiting the intake of sugar

- quality assessment of school lunches, which examines the school meals schemes

- assessing the effect of food and meals policies

- parent-funded food schemes in day care facilities and schools, and the school fruit programme

Development projects are underway to secure:

- an evidence-based investment in food and meals

- advice to schools and day care facilities that is based on risk assessment, and thus knowledge that is documented

- an AOK that is updated with new knowledge that the schools are requesting

- continuous new information on the website

- development of food and meal schemes as a whole

- support for day care facilities and schools in their work.

- Diet in a nutshell and the success criteria are thus continuously evaluated, and the website was updated in April 2007. Several areas have been evaluated. The website has been evaluated with regard to functionality, relevance and objectivity in relation to a qualitative target group. The flying squad has been evaluated with regard to work form and the effect of the flying squad's visits. The evaluation reveals that the flying squad performs satisfactorily with the work promoting health in the day care facilities, schools and municipalities that they visit. More information about the evaluation is available on www.altomkost.dk. 
- $\quad$ For more information, go to www.altomkost.dk.

- Contact: Karen Eriksen, Danish Veterinary and Food Administration, e-mail keri@fvst.dk.

\subsubsection{GetMoving}

Since 2005, the Danish Board of Health has completed an annual campaign in week 36 or 41 to promote physical activity. The GetMoving campaign in 2006 dealt with physical activity for 10-18 year olds. The message was that all children and young people should be physically active for at least 60 minutes a day - and preferably more. The purpose was primarily to give children and young people the desire to exercise, and to spread knowledge of the beneficial effects of physical activity on health.

This national campaign takes the inherent desire of children and young people to be more active as its starting point. Therefore, a central element of GetMoving is a film competition for children and young people with the theme "fun ways of raising their or their friends' pulse for 60 minutes a day". The films are put out on the net, and one is voted a winner. The GetMoving campaign was held in collaboration with the Danish Gymnastics and Sports Associations, The National Olympic Committee and Sports Confederation of Denmark, The Play Patrol, the Danish Forest and Nature Agency, and the Centre of Expertise for Health Promotion at CVU Sønderjylland, as well as many municipalities that organised local activities. The Danish Board of Health has produced a variety of materials that support the local activities such as posters for schools, and inspirational materials for municipalities. In addition, the Danish Board of Health collaborates with the National Association of Municipalities on facilitating the campaign.

Several areas of the campaign have been evaluated. Overall, it has been evaluated as good and "targets the children, where they are". The municipalities that have signed up for GetMoving feel it is very much in line with their own local initiatives, and therefore harmonizes well. Feedback from the other parties involved and municipalities indicates that it has been a good idea to disseminate the GetMoving message in an active, engaging manner, and to involve many different players. According to many of the respondents, the campaign could perhaps have been more visible - it had to attract attention in "a sea of many other campaigns/projects” - and needed to be more distinctive.

- $\quad$ The evaluation material and further information can be found on www.sst.dk, the website of the Danish Board of Health, under GetMoving, or on www.getmoving.dk.

- Contact: Just Bech Justesen, e-mail jbj@sst.dk. 


\subsubsection{6 a-day}

Started in 1999, the partnership 6 a-day was intended to provide the general public with the dietary advice "Eat fruit and vegetables -6 a-day". This is implemented through activities and campaigns to increase the Danes' dietary intake of fruit and vegetables. Involved in the partnership are the Danish Veterinary and Food Administration, the Danish Board of Health, the Motion and Nutrition Council, the Danish Cancer Society, the Danish Heart Foundation and the Fruit and Vegetable Industries. The message is based on solid scientific evidence that confirms that an increase in the fruit and vegetable intake to $600 \mathrm{~g}$ a day for adults and $400 \mathrm{~g}$ a day for children aged 4-10 years, does have an effect on the prevalence of cancer and cardiovascular disease. It also contributes to increasing the dietary fibre and to lowering the energy content.

6 a-day informs schools and companies about the fruit and vegetable scheme, and produces campaigns to promote the intake of fruit and vegetables. For children, there is Frugtfest (Fruit fest), which provides ideas for food at children's parties in which fruit and vegetables are the main ingredient. In 2007, there was a special initiative to promote the school fruit scheme, to provide all children with the opportunity to eat fruit during the school day.

Knowledge of the message is evaluated regularly. Studies on diet by the Directorate of Food, and the 6 a-day studies of the Danes' consumption of fruit and vegetables, reveal that the intake of fruit and vegetables is increasing, data that is supported by figures from Statistics Denmark ${ }^{17}$. At the same time, studies reveal that knowledge of the 6 a-day programme is increasing among the general public.

- $\quad$ For more information, go to www.6omdagen.dk.

- Contact: Susanne Tøttenborg, email st@6omdagen.dk.

\footnotetext{
${ }^{17}$ Source: 6-a-day website
} 


\section{Norway's initiatives for the health of children and young people}

\subsection{Legislation and state action plans}

One of the purposes of the Act relating to Food Production and Food safety, etc. (The Food Act) ${ }^{18}$ is to promote health. The Norwegian Food Safety Authority administrates the regulations in this area.

The Norwegian Directorate of Health is a state authority for the social and healthcare sector that works to improve dietary habits and to increase physical activity by the general public. In 2005, the Norwegian directorate of health published Norwegian recommendations for nutrition and physical activity that was based on Nordic Nutrition Recommendations 2004 Integrating nutrition and physical activity ${ }^{19}$, Recipe for a healthier Norway (2002-2003), and WHO Global Strategy on Diet, Physical Health and Health.

The government's Action Plan on Nutrition 2007-2011, and the Action Plan on physical activity 2005-2009, provides guidelines for policies within the areas of nutrition and physical activity. The government's Action plan on Nutrition (2007-2011) - a recipe for a healthier diet was presented in January 2007. Twelve ministries have participated in developing this plan. The purpose was to promote health and prevent disease through a healthier diet. Emphasis was placed on making it easier to choose healthily and to prepare good meals in nursery schools, schools and for the elderly, and to increase knowledge on food and nutrition. The initiatives were also intended to contribute to reducing social inequality in health. Children and young people were the focus, with nursery schools and schools mentioned as the central arenas. The offer of fruit and vegetables in day care facilities and schools should be increased. At the same time, lower prices on fruit and vegetables and higher prices on energy-dense and nutritionally poor foods were discussed as a means of promoting the intake of healthy foods.

Handlingsplan for fysisk aktivitet 2005-2009 - Sammen for fysisk aktivitet, Norge (Action Plan for Physical Activity 2005-2009 - Together for Physical Activity, Norway) is the result of a collaboration by eight

\footnotetext{
${ }^{18}$ Act 2003-12-19-124 relating to Food Production and Food safety, etc.

${ }^{19}$ Norske anbefalinger for ernæring og fysisk aktivitet, IS-1219, 2005, jf. (Norwegian recommendations for nutrition and physical activity) Directorate of Social and Health Care Services website www.shdir.no
} 
Ministries. Concomitantly, a Communication strategy 2005-2009 has been produced which is intended to increase knowledge on physical activity and health, and motivate the general pubic to lead an active lifestyle. The purpose of the action plan is to promote health and prevent disease through increased physical activity. The goal is to be achieved by restricting the factors that allow physical inactivity, and by drawing up cross-sectorial initiatives that promote physical activity in nursery schools and schools.

The arenas for these initiatives for the promotion of physical activity include creating better opportunities for active transport. A National cycle strategy was drawn up in 2003, and a national network of cycle cities illustrates the opportunities for improving cycling facilities and thereby promoting the cycle as a means of transport. Walking as a means of transport has also been the target of focus. Other important arenas central to promotion of physical activity are schools, work places, the health care sector, and residential areas and local communities.

The National Strategic Plan to equalize social health inequalities that was published by the government in 2007, includes measures to equalize socially dependent differences arising from diet and physical activity.

In the parliament report Early investments for life-long learning 20062007, the government states that it will introduce fruit and vegetable schemes in all schools and encourage the schools to facilitate physical activities.

A partnership for public health has been established in all the counties throughout Norway. Public health work requires cross-sectorial efforts if it is to succeed, because the premises for improved health lie within several societal sectors. Establishing partnerships is therefore desirable both regionally and locally. Partnerships as a work form and strategy generate a more committed, long-term and cross-sectorial collaboration on promotion of public health. The partnership model allows stronger anchoring in publicly-elected bodies and in normal planning and decision-taking processes. The model also provides a better basis for the participation in public heath work by voluntary organizations. Partnerships should prioritise nutrition and physical activity.

\subsection{State-initiated initiatives for nutrition and physical activity (national level)}

The Norwegian Directorate of Social and Health Services considers one of its primary objectives is to get the public to eat more fruit and vegetables and to reduce the intake of sugar and fat. Increased intake of fruit and vegetables to 5 portions a day is considered an important measure in improving the populations' diet and to be a good health investment. There is no difference in the recommendations for children and adults. 
Knowledge of what children and young people eat is important in assessing the nutrition situation, and is necessary to follow up and evaluate initiatives. A second series of nationwide dietary studies are now underway into the dietary habits of infants (6-12 months) and toddlers (24 months). The report from the dietary studies will be finalised in 2008 and will be available on www.shdir.no/ernaering.

The Directorate of Social and Health services recommends at least 60 minutes physical activity for children and young people and a minimum of 30 minutes a day for adults and the elderly. A working group has been appointed to evaluate whether there is a need for change in the current recommendations for physical activity in children and young people. This is the result of new documentation that has been published in recent years.

For the first time, a nationwide representative monitoring of physical activity levels, physical fitness and determinants for physical activity has been conducted for 9-15 year olds. This national monitoring programme will be repeated regularly. The report is available on www.shdir.no.

\subsubsection{Health in nursery schools}

In connection with the work Bra mat $i$ barnehagen (Healthy food in nursery schools), the Norwegian Directorate of Health and Social Affairs published new guidelines on food and mealtimes in nursery schools in autumn 2007. The guidelines contain concrete recommendation for meals, and for food and drink. The purpose of these guidelines is to act as a guiding tool in the work with food and meals in nursery schools. At the same time, the guidelines highlight food and meals that promote health, enjoyment and learning. The target group for the guidelines are not only private and municipal nursery schools and their staff, but also employees and others who are interested in or work with food and health in nursery schools.

There is no legislated requirement for nursery schools to follow the guidelines, but in the comments to paragraph 11 in Forskrift for miljørettet helsevern $i$ barnehager og skoler (Regulations for environmental health protection in nursery schools and schools) they are advised to base work with food and mealtimes on these guidelines. The guidelines are distributed to all nursery schools, all municipalities, counties, county governors, health centres, voluntary organisations and other collaboration partners, with an accompanying letter. Materials for the guidelines will be prepared directed at the target group. These are expected to be ready later in the autumn of 2007. The Directorate of Health and Social Affairs received NOK 1 million in 2007 to get the programme started.

- $\quad$ For more information, go to www.shdir.no/ernaering/barnehage.

- Contact: Kaja Lund-Iversen, Norwegian Directorate of Health and Social Affairs. 
The Seafood project - increased consumption of seafood by children and young people - is a cooperation project initiated by the Norwegian Ministry of Fisheries and Coastal Affairs, the Ministry of Health and Care Services, and the fisheries industry. The primary objective of the project is to promote an increased intake of seafood products particularly among children and young people. One of the sub-objectives of the Seafood project is to promote healthier dietary habit and to increase the consumption of fish and shellfish in nursery schools.

There have not previously been continuous efforts directed at nursery schools with regard to seafood products. There is therefore a need to develop good tools and models if the goal of increased intake of fish and shellfish is to be realised.

Three pilot counties have been selected to participate in the development work in 2007-2008. They will each receive NOK 200,000 to implement the project. Competence-building courses will be offered. In the long-term this will become a national project, and the work within the pilot projects will be evaluated.

In 2007, a total of NOK 4 million was allocated to the Seafood project, which is led by the Norwegian Seafood Export Council. The Norwegian Directorate of Health and Social Affairs and the Norwegian Institute for Fisheries and Nutrition Research are both participating in the study.

- $\quad$ For more information, go to www.shir.no/ernaering/barnehage

- Contact: Kaja Lund-Iversen, Norwegian Directorate of Health and Social Affairs.

\subsubsection{Health in schools}

The project Fysisk aktivitet og måltider $i$ skolen (Physical activity and meals in schools) tests several models for healthy meals and daily physical activity in schools. This has been started by the Ministry of Education and Research and the Ministry of Health and Care Services. The project was completed in lower compulsory schooling (1st-10th class) during 2004-2007, and in the upper secondary schools during 2005-2008. The primary goal of the project is to develop models that sustain daily physical activity and good frameworks for healthy meals in schools every day. The most important goals for this project were to select Best Practice and to advise local school management on success factors. The project has been evaluated. Read more about this project in subsection 7.3.1.

Skolefrugt (School Fruit) is a nationwide subscription scheme for fruit and vegetables in compulsory schooling that is subsidised by the state by NOK 1.00 per pupil per day. The Directorate of Health and Social Affairs is responsible for this scheme.

The autumn of 2007 saw the start of the scheme with free fruit in schools for schools at lower secondary level. All pupils at these schools 
will be offered a free piece of fruit or vegetable every day. The offer will cover about $45 \%$ of all pupils in the 1st-10th classes in Norway. The government has allocated funds for this project in the revised national budget 2007. Students at schools that only have 1st-7th classes will not receive the same offer from the autumn. However, funds are expected to be allocated to offer fruit and vegetables every day from 2008/2009. Schools with 1st-7th classes will be encouraged to continue with the subsidized subscription scheme Skolefrugt (School Fruit. Read more about this project in subsection 7.3.

In the autumn of 2008, the Directorate of Health and Social Affairs will publish a new revised cookery book for pupils in lower secondary school called Kokebog for alle (Cookery book for everyone). The purpose of the cookery book is to stimulate enjoyment of food, and to inspire both young people and adults to prepare good and healthy food based on the authorities' dietary recommendations. The new cookery book is based on experiences from the cookery book "From buns to burritos" that was distributed free to pupils in lower secondary education from 1998-2006. The book is to be used in connection with education and practical food preparation lesions in school. The book contains more than 200 recipes for healthy meals, information on raw materials and healthy dietary advice. The pupils can take the free cookery book home. The Cookbook for Everyone is financed by a collaboration between the health authorities and the food and grocery industry. The cookery book will also be on sale in bookshops and supermarkets.

- $\quad$ For more information go to www.shdir.no/ernaering/skole.

- $\quad$ Contact: Anniken Owren Aarum, The Norwegian Directorate of Health and Social Affairs.

Undervisningsmateriell for grunnskolen i hygiene, ernœring og merking av mat (Study material for compulsory schooling in hygiene, nutrition and labelling of food) is pedagogic material that is available on http://www.matportalen.no. The purpose is to increase children's and young people's knowledge on hygiene, nutrition and labelling of food. The material has been developed in collaboration between the Ministry of Agriculture and Food, the Ministry of Health and Social Services, and the education authorities. The material is free and can be used by everybody.

The Competence Strategic Plan 2005-2008 - for teachers in obligatory schooling. To increase the possibilities of offering physical activities to all pupils every day in schools, it is important that teachers, school principals and others have competence in improving the quality and awareness of physical activities for pupils. In connection with Knowledge Promotion, the Ministry of Education has taken an initiative for a competence strategy Kompetanse for utvikling (Competence for development), Strategy for competence development 2005-2008, in which physical 
activity is one of the five prioritised areas. The competence strategy includes general post-training for all employees and further training of sports and other teachers. About 20 university colleges and universities offer competence promoting courses and guidance to schools that wish to incorporate daily physical activity as part of the strategy.

An overview of all participating university colleges and universities is available on http://www.nih.no/kunnskapsloftet.

In 2005, the school owners received a total of NOK 300 million from the State for the competence development strategy and, in 2006, NOK 375 million. In 2007, the school owners received a further NOK 375 million for competence development.

- $\quad$ For more information and evaluation of this initiative, go to www.udir.no.

- Contact: Anita Andaas Aadland, The Norwegian Directorate of Health and Social Affairs.

Parent guidance programme is a health promoting initiative that offers support to parents in the carer and guardian role. The programme was established in 1995, and is run in cooperation between 4 ministries. The goal of the programme is to create fora where parents in the municipalities (schools, nursery schools, health care centres) can meet. Here they will be able to exchange experiences and discuss issues on bringing up children. Using actual topics, practical materials such as handbooks, videos and topic leaflets are produced as tools to stimulate conversations with parents. A leaflet on physical activity has now been produced and will be available from autumn 2007.

The leaflet Barn og fysisk aktivitet - med hovedvekt på aldergruppa 0-16 år (Children and physical activity - with main emphasis on age group 0-16 years) will also be available on the website www.shdir.no

\subsubsection{The health services as an arena}

Guidelines for prevention and treatment of overweight and obesity in children and young people are currently in preparation. The guidelines will be completed at the end of 2007, and will be available on the website www.shdir.no.

Retningslinjer for veiing og meling $i$ helsestasjons- og skolehelsetjenesten (Guidelines for weighing and measuring in the health care and school health services) are under preparation. The guidelines are scheduled for completion in summer 2008 and will be available on www.shdir.no.

Norway and Sweden are collaborating on a recommendation manual on physical activity - FYSS 2 . The target group is primarily health care professionals. FYSS 2 will cover recommendations for children, young 
people, adults and the elderly, specific recommendations for use of physical activity in relation to certain diagnosis, how to motivate to increased activity levels, determinants for physical activity, presentation of various forms of exercise, etc. FYSS 2 will be available during winter 2008.

- Contact: Anita Andaas Aadland, The Norwegian Directorate of Health and Social Affairs.

\subsubsection{Raising competence of health care personnel}

In order to increase the levels of physical activities and healthier nutrition for the purpose of prevention, treatment and habilitation/rehabilitation, there is a strong need for more knowledge among health care personnel. In Norway, the health authorities in collaboration with the medical faculties are examining the content of foundation courses in medical education. The content of medical studies has been mapped with respect to physical activity and nutrition (and also in part, tobacco), and newlyqualified doctors have completed a knowledge test at the four faculties of medicine in Norway. Here they have looked at the coming doctor's level of knowledge on use of physical activity and nutrition in prevention, treatment and habilitation/rehabilitation. Briefly summarised, the study concludes there are grounds for considerable improvement in this professional group's knowledge in these areas. The report Medisinerstudentenes kunnskapsnivå om fysisk aktivitet, ernæering, tobakk og helse (Medical students' level of knowledge on physical activity, nutrition, tobacco and health) summarises the results of the study and will be shortly available on www.shdir.no. Contact: Anita Andaas Aadland, The Norwegian Directorate of Health and Social Affairs.

As a continuation of the report, the Norwegian Directorate of Health and Social Affairs will continue the dialogue with the medical faculties in order to determine how the level can be raised.

\subsection{Best Practice}

\subsubsection{Physical activity and meals in schools}

The project Fysisk aktivitet og måltider i skolen (Physical activity and meals in schools) was started in 2004 as a national campaign by the Ministry of Education and Research and the Ministry of Health and Care Services. The main purpose of this project is to develop models to integrate one hours' daily physical exercise into the school day and good frameworks for healthy meals. The Ministry of Education and Research and the Ministry of Health and Care services have been responsible for 
implementation of the project in cooperation with the chief administrative officers of the county.

All the country's schools were invited to apply for project funds. A total of 350 schools (about 10\% of the countries compulsory schooling) participated in the project, of which 180 schools have been monitored and compared with a similar number of control schools. Below, follows a list of the criteria for the schools' participation:

- Physical activity and meals are integrated/anchored in a holistic plan for the environment and learning in the school

- The school days are organised so that all pupils get at least an hour's physical activity a day

- The Norwegian Directorate of Health recommended guidelines for school meals must be followed

- Pupils must be involved in an active manner

- Parents/guardians must also be involved

- The school participates actively in the work of evaluating the initiative and is represented at network meetings

Evaluation of the project presents two models, which can ensure implementation of daily physical activities within the schools' existing frameworks:

1. The subject model - physical activity as a method to achieve competence targets in subjects.

2. The lunch break/morning and afternoon break model - organised physical activity in the lunch break or in expanded morning/afternoon breaks

Every third primary school and half of the lower secondary schools in the project have introduced at least half an hour's continuous physical activity during school time. Almost $60 \%$ of the primary schools and $40 \%$ of the lower secondary schools have integrated physical activity into lessons. $40 \%$ of primary schools and half of lower secondary schools have included the activity in a break, or found another solution.

The evaluation also presents two models for facilitating school meals or a combination of these:

1. Daily offer of fruit and vegetables

2. Offer of a complete meal - the model is based on providing everybody or a small group of pupils the offer of a complete meal at school. 
Some of the schools have based both models on the pupils taking food from home, while others offer food provided by the school. Twice as many pupils at schools that participated in the project received the offer of fruit and vegetables than those at other schools. Most schools have at least a 20-minute lunch break.

Almost $70 \%$ of primary schools and half of the lower secondary schools that were included in the intervention schools believed that the pupils were, to a high or very high degree, more concentrated in lessons. About half of the schools saw a positive development in the social environment among pupils. Every third school reported less bullying.

Guidelines have been drawn up which describe the models and initiatives that the participating schools have implemented. The guidelines provide information on the organisational prerequisites for success and a DVD with examples from the schools. The guidelines are directed at schools and school owners.

- $\quad$ Guidelines and materials are available on the net at: http://skolenettet.no/lom and www.utdanningsdirektoratet.no under

Underveis i Kunnskapsløftet (Underway with Knowledge promotion).

- Contact: Nina Strand Ølnes and Hanne Kristin Larsen, The Norwegian Directorate of Health and Social Affairs.

\subsubsection{School fruit}

The nationwide subscription scheme Skolefrugt (School fruit) is part of the authorities' efforts to increase pupils' intake of fruit and vegetables in compulsory schooling. School fruit is a co-operation between the Directorate of Health and Social Affairs and the Information Office for Fruit and Vegetables. This has been a nationwide scheme since 2004. The first pilot project started in 1996. In 2007, 45\% of the country's compulsory schools participated in the scheme and about $30 \%$ of pupils in the schools participated.

The parents pay the subscription, which costs about NOK 2.50 per day. The authorities support the scheme by NOK 1.00 per pupil per day. The pupils are offered a piece of fresh fruit or vegetable such as apples, pears, oranges, bananas, carrots, kiwis, nectarines or clementines depending on the season.

During this time, initiatives have been developed and implemented based on user experiences. School fruit has been legislated through Forskrift om tilskudd til prisnedskriving av frukt og grunnsaker i grunnskolen (Regulations on subsidies for price reduction of fruit and vegetables during compulsory schooling). This has been necessary to achieve a varied selection of good quality. The participating schools are provided with a cooler cabinet and other aids for storage as well as information 
material. An administrative tool has been developed on the net for wholesalers, schools and parents who use the scheme for subscribing and payment to lighten administration of the scheme for the school. People who do not have access to internet can use a service telephone. Good examples of how the scheme has been organised in the schools, as well as facts and tips, are available on www.skolefrukt.no.

Evaluation of the subscription scheme, School fruit, has demonstrated that the pupil's consumption of fruit and vegetables increases. However, it must not be forgotten that the pupils that participate tend to have healthier dietary habits and are more physically active than those that do not participate. Parents of pupils that subscribe to the scheme are distinguished from those that do not subscribe in as much as they are older, have a higher education and income, and smoke less. A trial project for one year with free fruit and vegetables to pupils in $6^{\text {th }}$ grade, has shown that not only did all pupils eat more fruit and vegetables, but those that ate a lot of sweets and snacks also reduced their intake of these products.

The government, in an extension of its work to remove social inequalities in health, wishes to introduce the scheme with fruit and vegetables to all pupils in compulsory schooling. From the autumn of 2007, all schools with lower secondary grades will be offered the scheme of daily free fruit or vegetables for the pupils. The offer will cover about $45 \%$ of all the country's pupils. In addition, certain schools in Norway that only have primary grades will be offered free fruit and vegetables, so that experiences can be gained from implementation of a free fruit and vegetable scheme for the youngest grades in the schools.

- $\quad$ For more information, go to www.skolefrukt.no

- Contact: Tore Angelsen, The Information Office for Fruit and Vegetables and Hanne Kristin Larsen, the Norwegian Directorate of Health and Social Affairs.

\subsubsection{Active schoolchildren}

Aktive skolebarn (Active schoolchildren) is collaboration between The Norwegian Directorate of Health and Social Affairs, Norwegian Public Roads Administration, The Norwegian Council for Road Safety, and the Police. The goal of the project is increased numbers of children walking or cycling to school under safe conditions. Target groups for the project are children and parents/guardians of children in compulsory schooling. The initiatives stimulate collaboration between schools and homes, and all schools are invited to become involved in this extremely important area.

As part of the programme, information, educational material and parent's advice have been produced, as well as an internet site with tips and advice on how safe and active school routes can be developed. Active 
schoolchildren wishes to create attention in the media on the importance of physical activity, traffic schools and safe school routes, disseminate knowledge and information to parents, and to promote local measures and activities. Read more about it on www.aktiveskolebarn.no.

In 2005, 7,500 schoolchildren and their parents were asked how they got to and from school, and how they experienced the school route. Together with a pre-study from 2002, this study acted as an evaluation of the project Active Schoolchildren. Looking at all schoolchildren in Norway, there have not been significant changes with respect to school transport from 2002 to 2005. In 2005, as in 2002, 43\% of children walked to school, and $25 \%$ went by car. On the other hand, if we look at those schools that participated in the "Walk-to-school" actions, there has been a $50 \%$ increase in the probability that children have walked or cycled to school. During this same time period, there has been a considerable rise in the number of parents that thought that the school route was dangerous; from $9 \%$ in 2002 to $17 \%$ in 2005. The evaluation report "Barns fysiske bomiljø, aktiviteter og daglige reiser” (report 869/2007) (Children's physical local environment, activities and daily travel) is available on www.toi.no.

Contact: Nina Strans Ølnes, The Norwegian Directorate of Health and Social Affairs. 



\section{Sweden's initiatives for the health of children and young people}

\subsection{Legislation and action plans}

The purpose of the Swedish Food $\mathrm{Act}^{20}$ is to secure a high level of protection of people's health. Promotion of healthy dietary habits is not mentioned specifically.

The National Food Administration is a state authority that works to promote good dietary habits. The National Food Administration draws up the Swedish nutrition recommendations and other forms of advice and recommendations for good dietary habits. This includes advice on food in nursery schools, schools and in work places, advice to pregnant and breastfeeding women, and on food for parents with infants and toddlers. Examples of tools used to make it easier to choose healthy food are the Keyhole symbol (signposting), the Food plate model and the Food circle. The National Food Administration also deals with foodstuff recommendations for various foodstuff groups. The National Food Administration's 5 kostråd 2005 (5 dietary tips 2005) is based on the latest research within nutrition, and knowledge of the eating habits of the Swedish population. It has been important for the National food Administration that the dietary advice has been perceived as positive and that it stimulates change ${ }^{21}$.

At the government's request, the National Food Administration and the Swedish Institute of Public Health drew up a proposed draft for an action plan for good dietary habits and increased physical activity in the population in February $2005^{22}$. Three measurable outcomes were set for good dietary habits:

- increased consumption of fruit and vegetables (children (4-10 years) should eat about $400 \mathrm{~g}$ fruit and vegetables per day)

- increased consumption of keyhole labelled food

- reduced consumption of foodstuffs such as sweetened drinks, sweets, ice-cream, snacks, cakes and alcohol (max. 15\% of energy intake should be covered by these foodstuffs)

\footnotetext{
${ }^{20}$ Livsmedelslag (2006:804) (The Swedish Food Act)

${ }^{21}$ Website of the National Food Administration www.slv.se

${ }^{22}$ Sammanfatning av regeringsuppdrag Goda matvanor och ökad fysisk aktivitet - underlag til handlingsplan, Statens folkhälsoinstitut www.fhi.se (Summary of the Government's remit Good food habits and increased physical activity - documentation for an action plan, The Swedish National Board of Public Health).
} 
The proposals include:

- preparation and distribution of guidelines for all meals in nursery schools

- incorporation of the term "health" in the objects clause of the new School Act. The School Act should stipulate that meals served in nursery schools and schools must be in compliance with the current national nutrition recommendations.

It is acknowledged that an important target group in the efforts against overweight is children and young people, and that the work with promoting healthy diet and physical activity demands cross-sectorial collaboration.

In Förslag till en nationell handlingsplan för barns miljö och hälsa (Proposal for a national action plan for children's environment and health) support is provided for the preparation of a national action plan for good dietary habits and increased physical activity with particular focus on children and young people. The underlying documentation for such an action plan has been drawn up.

\subsection{State-initiated initiatives for nutrition (national level)}

Campaigns on healthy dietary habits have not been instigated at a national level in Sweden apart from information on the website www.slv.se and printed materials. Campaigns and regular activities designed to promote healthy dietary habits and physical activity take place primarily at regional and local levels.

\subsubsection{The keyhole symbol}

The keyhole symbol is a symbol that helps the consumer to choose healthy food: The National Food Administration's keyhole symbol is intended to help the consumer find healthier alternatives both in retail outlets and in restaurants. Keyhole-labelled foodstuffs contain less fat, sugar and salt, and more dietary fibre than other foodstuffs of the same type. The keyhole symbol is a well-known and requested symbol among consumers in Sweden, and is used actively by retailers. It is launched in commercials as a market advantage with highly positive benefits.

- $\quad$ For more information: www.nyckelhalet.se

- Contact: Anita Laser-Reuterswärd, The National Food Administration 


\subsection{State-initiated initiatives for physical activity (national level)}

\subsubsection{Physical activity on prescription}

Fysisk Aktivitet på Recept (FaR) (Physical activity on Prescription) is today used by about half of Sweden's Hälsocentraler (health care centres). The concept entails prescribing physical activity in the same way as medicines, i.e. the topic is discussed, an FaR is prescribed, and the results of treatment is followed up. Physical activity can be used both in a prophylactic context and as treatment. The dosage of the prescription must be customised to the individual with respect to intensity, treatment period and frequency as well as type of activity.

$\mathrm{FaR}$ is considered to be a supplement to or a substitute for medication. The prescriber must be competent, and have sufficient knowledge of the patient's health, because some conditions do not permit certain types of activity. It is also important that the patient is given help, guidance and support to effectuate the activities. Follow up by the Health and hospital services is also important for the success of the treatment, because the patient is followed up and receives help to get going with a more physically active lifestyle.

National statistics on FaR are currently being compiled.

- $\quad$ For more information: www.fhi.se

- $\quad$ Contact: Helen Askebro, The Swedish Institute of Public Health

\subsubsection{Activity stimulating environments}

The Swedish Institute of Public Health has, at the request of the government, started cross-sectorial and long-term development work on the significance of built-up areas on physical activity. Built up areas include public indoor environments and outdoor environments in the proximity of built up areas such as leisure facilities and the road network, as well as parks and natural areas.

Development work will include studies of which factors in the local community that promote physical activity in children, adults and the elderly, but will also identify research needs and effective methods and efforts. Gender and age will also be considered in this work.

The environments in focus are: Footpaths/pavements and cycle tracks, the local environment in built up areas, school yards and play areas, indoor environments and recreational areas near the home.

- $\quad$ For more information: www.fhi.se

- Contact: Anna Stamblewski, The Swedish Institute of Public Health 


\subsection{Regional initiatives for physical activity}

\subsubsection{The Bunkeflo Project}

The Bunkeflo project started in the autumn of 1999, and is collaboration between schools, sports associations and universities. The project has received recognition at the highest political, sports and research level Today, the project is a well-known welfare project that has been in the media throughout the country.

The Bunkeflo project was started at Ängslätts School in Bunkeflostrand. The local sports association helped to provide 1 to 2 hours physical activity a day for the children - every day. For children starting in the 1st grade, daily physical activity is an obligatory subject. Now, children up to 4th grade have physical activity every day.

- $\quad$ For more information: Conny.Lindvall@malmo.se, tel.: 040-34 1000.

\subsection{Regional initiatives for better dietary habits and physical activity}

8.5.1 Lev livet lättere - aktuelle indsatser mod overvcegt og fedme hos børn i Jönköping län (Live life lighter - initiatives against overweight and obesity in children in Jönköping county)

The programme in Jönköping is directed at single people, children and families. It is effective both as preventive and treatment intervention. The programme is completely in line with the Action Plan for better dietary habits and increased physical activity presented by the National Food Administration and the Swedish Institute of Public Health. The dietary advice is based on the Nordic Nutrition Recommendations and the National Food Administration guidelines. The recommendations in the pedagogy plan from the National Agency for Education have formed the basis for physical activity.

Goals, methods, activities and repeated measurements have been documented.

- $\quad$ For more information: www.lj.se/folkhalsa, www.lj.se/barndialogen

- Contact: Linda Frank.

\subsubsection{The Norsjö Project}

The Norsjö initiative was started in 1985 as a result of high mortality due to cardiovascular disease. The questions this project tries to answer are "What is the reason for this" and "What can we do". The Norsjö project 
has attempted to positively influence people's dietary habits under the motto "It is better that many change a little, than few change a lot".

The sub-goals are to:

- act early to prevent high blood pressure

- increase awareness of the relationship between various risk factors and cardiovascular disease and diabetes

- develop and stimulate broad public participation and influence in preventive work

- develop and validate methods for concrete primary efforts in preventive work targeting the public

- create focus and stimulate research and development work within this area

- stimulate preventive activities and encourage a broad debate on this public health work

- evaluate and document the experiences from both Norsjö and the county

The Norsjö initiative is an extremely driven project. The most probable explanation is the very broad front of the efforts, but some key factors with particular importance are:

- solid anchoring at local level

- a scientific foundation

- implementation of broad education efforts

- the strategic decision to give the project both an individual and a general population image

- the project was not top-managed

- a doctor (Gideon Hдllsten) with roots in the area

Study: Norsjöprojektet - en svensk modell för lokalt folkhälsoarbete, 1999 (The Norsjö project - a Swedish model for local public health work) by Kurt Bohman

- $\quad$ For more information: Norsjö municipality, http://www.norsjo.se

\subsection{Best Practice}

\subsubsection{Meals in nursery schools and schools}

The School Act stipulates that "Pupils in compulsory education must be offered free meals" (Act 1997:1212). The act also covers special schools, Sámi schools, and state-supported independent schools. In practice this means that one or more dishes of prepared food, a salad bar, drinks, and 
bread are normally offered. There are similar schemes in nursery schools and upper secondary schools, but here the institutions are entitled to demand payment for the meals.

- $\quad$ For more information: www.skolverket.se

- Contact: Information, The National Agency for Education, tel.: 08-527 33200

\subsubsection{Increased physical activity in schools}

On 27 February 2003, the compulsory schooling's pedagogic plan for nursery schools and after-school facilities was amended with effect from 3 June 2003: "The school shall strive to offer all pupils daily physical activity throughout the school day."

Evaluation: Refer to Children in Movement - seven school examples from the Swedish Sports Confederation

- $\quad$ For more information: www.rf.se,

- Contact: The Swedish Sports Confederation, tel.: 08-699 6000

\subsubsection{Guidelines for meals in nursery schools and schools}

In 2006, the National Food Administration was given the remit by the government to draw up guidelines for food in schools, nursery schools, day care facilities, after-school facilities and upper secondary schools. The guidelines were published in March 2007. The guidelines apply for the time the children and young people are in the institutions, i.e. they include breakfast, lunch, snacks, and food for trips and parties. The guidelines apply to all personnel that have anything to do with serving or selling food in schools and nursery schools. These are not only decisiontakers in municipalities, dieticians, retailers, school principals, kitchen personnel and pedagogic personnel, but also parents. Each municipality, nursery school, school and personnel group decide and plan in detail the food and meal policies.

- $\quad$ For more information: www.livsmedelsverket.se

- Contact: Ulla Kaisa Koivisto-Hursti, The National Food Administration 


\section{Finland's initiatives for the health of children and young people}

\subsection{Legislation and action plans}

The purpose of the Finnish Food $\mathrm{Act}^{23}$ is to ensure good quality, healthy food, but does not mention "promotion of healthy dietary habits".

The principle decision on the Public Health Programme Health $2015^{24}$ by the Finnish government draws up guidelines for the Finnish health public health programme and for the Finnish health policy with a 15 year timeline. The programme stipulates eight goals that define the results to be achieved in the various phases of life.

For children, the goals are:

- The well-being of children must be increased and their health improved while the symptoms and diseases that are associated with insecurity decline markedly.

- The important role of day care facilities and schools in the life of children is emphasised.

The Finnish Public Health programme focuses on gripping the reasons why certain groups in society become marginalised. The Ministry of Social Affairs and Health has appointed a Committee for development of health-promoting physical activity which is to define challenges, set goals and draw up proposals for action plans in this area.

The National Nutrition Council is an expert body that is appointed every third year by the Minister of Agriculture and Forestry. Its task is to monitor and develop the field of nutrition through compilation of nutrition recommendations, action plans and follow up of how initiatives are implemented and their effect on public health.

The Finnish National Nutrition Council recommends that the population should eat plentiful quantities of vegetables, berries and fruits, at least five a day, in total at least $400 \mathrm{~g}$. There is no differentiation between adults and children. The intake of refined sugar should not exceed $10 \mathrm{E} \%$. This applies in particular to children. Recommendations for physical activity are in line with those of the other Nordic countries with a mini-

\footnotetext{
${ }^{23}$ Livsmedelslag (The Finnish Food Act) 13.1.2006/23

${ }^{24}$ Government Resolution on the Health 2015 public programme 2015, The Ministry of Social Affairs and Health, publication 2001:5
} 
mum of 60 minutes for children and 30 minutes for adults. It is further emphasised that the level of physical activity should be increased to 60 minutes for adults to avoid increases in weight.

The National Nutrition Council has prepared an Action Plan for putting the national nutrition recommendations into practice. This prioritises prevention of obesity and promotion of healthy food. It is pointed out that to secure nutritional quality in nursery schools and schools, quality criteria must be drawn up ${ }^{25}$.

\subsection{State-implemented initiatives for a healthier lifestyle}

A large number of the initiatives implemented to promote a healthier lifestyle in Finland have been conducted by municipalities and NGOs, as well as businesses. There are therefore far more initiatives in Finland at levels other than those included in this catalogue.

JALOIN is a project implemented as a result of the Ministry of Transport and Communications policy to promote walking and cycling. Crosssectorial co-operations will be used to improve the opportunities for walking and cycling in Finland.

\subsubsection{Information}

The most recent Action programme includes proposals on how to implement dietary recommendation in society. However, because the Finnish efforts on health promotion are conducted in the municipalities, NGOs and with the assistance of private industry, the State's role is restricted to publishing information material. Nevertheless, promotion of the dietary recommendations still requires close co-operation between the parties.

The National Nutrition Council has provided three dietary models for use for educational purposes. In addition, a poster for the "Plate model", illustrating how to compose a healthy meal, has been produced. A brochure encouraging physical activity and choosing healthier food in accordance with the dietary recommendations has also been published. Finnish recommendations state that there should be a balance between energy intake and consumption, a balanced nutrient intake, an increased intake of dietary fibre, a reduced intake of refined sugar, a reduced intake of hard fats, and a reduced intake of salt. The portion of soft fat should preferably be increased.

The Finnish dietary recommendations drawn up by The National Nutrition Council are derived directly from the recommendations of the Nordic Nutrition Recommendations. The National Health Institute (KTL)

\footnotetext{
${ }^{25}$ Statens näringsdelegation 2003, sammandrag av åtgärdsprogram för att omsätta de nationella näringsrekommendationer i praktiken (wwwb.mmm.fi) (The State Nutrition Delegation 2003, Summary of measures to apply the national nutrition recommendations in practice)
} 
publishes The National Nutrition Council's recommendations for nutrition and physical activity on their website ${ }^{26}$.

\subsubsection{Initiatives in day care facilities and schools}

Finland provides meals for children in nursery schools and schools ${ }^{27}$. Furthermore, sports activities and health education are obligatory in compulsory education. The subject also includes dietary education. Educational material called McUrho on the consequences of unhealthy lifestyles has been prepared for pupils. The material has been developed in a collaboration between the Finnish Heart Association and the Finnish Cancer Organisation. There are no other campaigns at a national level that target healthy dietary habits in children and young people ${ }^{28}$.

The Ministry of Social Affairs and Health has instigated a strategy for health-promoting physical activity (HEPA). The goals for children and young people are to increase the opportunities for physical activity in nursery schools, schools and families. The strategy also emphasises that cross-sectorial efforts are essential if the goals are to be realised. HEPA is described in more detail in subsection 9.4.

\subsection{State-implemented monitoring projects}

Several initiatives have been instigated by The National Health Institute with respect to monitoring:

- In collaboration with the Oulu University Institute of Dentistry, Finnish Bread Information and the Finnish Heart Association, children's diet and well-being in the $7^{\text {th }}-9^{\text {th }}$ grades were investigated in 2006-2008

- In collaboration with Kuopio University, the diet and physical activity status of 6-7 year olds was investigated. The purpose of this project is to find ways to promote healthy food to 6-7 year olds, and to increase the amount of physical activity. The target group for these efforts is the entire family.

The National Center for Research and Development in Welfare and Health instigated a monitoring project in 1995 called The School Health Promotion (SHP) Study. The purpose of this study is to strengthen the planning and evaluation of health-promoting activities in municipalities and schools. Questionnaires are used to collect data. These are handed out

\footnotetext{
${ }^{26}$ www.ktl.fi

${ }^{27}$ A questionnaire for use with the NMR project on a joint catalogue of major initiatives in the Nordic countries promoting healthy dietary habits and lifestyle, p. 19

${ }^{28}$ A questionnaire for use with the NMR project on a joint catalogue of major initiatives in the Nordic countries promoting healthy dietary habits and lifestyle, p. 15
} 
in April to young people aged 14-18 years in the 8th and 9th grades and upper secondary education. The questionnaires cover topics such as living conditions, the school as a workplace, health attitude and health status. $90 \%$ of all municipalities participate in the project.

- $\quad$ For more information:

http://info.stakes.fi/kouluterveyskysely/EN/index.htm

Since 1977, Tampere University has worked on the Adolescent Health and Lifestyle Survey. This monitors the health and health-related lifestyle of 12-18 year-olds using questionnaires that are sent out every other year. This study contains comprehensive data on the development of young people's health and health-related attitudes.

For more information, contact Professor Arja Rimpelä, arla.rimpela@uta.fi.

\subsection{Best Practice}

\subsubsection{The Development Programme for the Prevention and Care of} Diabetes (DEHKO 2000-2010)

DEHKO is Finland's national programme against diabetes. The purpose of the programme is to prevent type 2 diabetes and diabetes-related complications, to improve the quality of the treatment of diabetes and to support diabetes patients' self-management. DEHKO designs new action models for health care that are implemented throughout Finland.

DEHKO has clear goals to be achieved before 2010. In addition there are 25 concrete action recommendations, many of which have already been achieved.

The programme is coordinated by the Finnish Diabetes Association, and is the first national programme in the world that both treats and prevents type 2 diabetes. DEHKO is evaluated regularly.

FIN-D2D is a sub-project under DEHKO, the purpose of which is to implement the Finnish programme for prevention of type 2 diabetes in the primary healthcare sector, and to develop new treatment methods. This is achieved by the use of healthcare facilities in workplaces, and by testing the feasibility of the programme. The ultimate goal is to prevent type 2 diabetes and overweight through three strategies: The high-risk strategy; The strategy for early diagnosis; and The management and population strategy. This is a society-based programme that is based on scientific methods according to a specific evaluation plan that includes investigations, studies and pre-studies. In spring 2007, the FIN-D2D rationale and design was published in the International Journal of Circumpolar Health. 
Collection of data is conducted by the primary healthcare sector and in healthcare facilities in workplaces. Lifestyle changes are evaluated with respect to the incidence of type 2 diabetes and compared with control groups. People in the high-risk group are followed up with annual examinations.

FIN-D2D evaluates both the efficacy and the cost-effectiveness of new prevention and treatment practices.

- $\quad$ Contact: Dr. Timo Saaristo.

- $\quad$ For more information, go to www.diabetes.fi.

\subsubsection{Health Enhancing Physical Activity (HEPA)}

In 2002, the Finnish government instigated the project Health Enhancing Physical Activity (HEPA). In recent years, the HEPA project has been distributed at a national level. The project is under the auspices of The Ministry of Social Affairs and Health, which together with representatives from other relevant ministries and interest organisations, administrates the programme. During the first three years, around 40 projects have been initiated by various ministries.

HEPA focuses on promoting physical activity across the entire Finnish population. Emphasis is placed on cross-sectorial co-operation to promote physical activity in differing age groups, building up local areas and local offers that promote physical activity, as well as strengthening HEPA in the municipalities. There is particular focus on passive groups and groups that will experience significant improvement from increased physical activity. Children, young people and the elderly are the primary target groups. Information emphasises the importance of daily activity and developing circumstances that promote physical activities.

HEPA works within the following areas:

- Organisation and funding of HEPA.

- The structure of local communities and their provisions that promote physical activity

- HEPA for life

- Incorporation of HEPA in the municipalities' health policies

- Education and research within HEPA. 
HEPA is also involved in the Young Finland movement, which has developed a code of ethics for the promotion of children's involvement in physical activity. A similar code of ethics was also drawn up for all sports organisations. The Move for Health Day is another important umbrella event for various activities ${ }^{29}$.

- $\quad$ For more information: Mari Miettinen, Ministry of Social Affairs and Health, email: mari.miettinen@stm.fi

${ }^{29}$ Nutrition, physical activity and prevention of obesity: Recent policy developments in the WHO European Region. Final draft - unedited, June 2007.

Mari Miettinen, Senior Officer National HEPA strategy and its implementation in Finland. 


\section{Iceland's initiatives for the health of children and young people}

\subsection{Legislation and action plans}

The purpose of The Foodstuffs Act ${ }^{30}$ is to ensure as far as possible the quality, safety and healthiness of foodstuffs.

Iceland's national health plan The Icelandic National Health Plan to the year 2010 and the action plan from the Public Health Institute of Iceland Action Plan 2006-2010 include the following goals as means of promoting a healthier lifestyle:

- to promote and map the increased consumption of vegetables and fruit in accordance with the goals set by the Public Health Institute of Iceland/Iceland's Nutrition council, at least five portions a day.

- to encourage schools to promote a healthier lifestyle

- to promote education and initiatives targeting healthier lifestyles in children, parents and teachers.

- to reduce the number of overweight 9 year-olds to less than $20 \%$ and the numbers of those who are obese to less than $4 \%$.

In 2006, the Prime Minister's office published a green paper that contained 67 action proposals for promotion of public health through promotion of healthier food and increased physical activity. Emphasis was placed on contributing to making it easier for individuals to choose healthily, to increase physical activity, to prepare good meals in nursery schools, schools and in the workplace, and to strengthen knowledge about food. Collaboration between public and private parties is encouraged, and involves the Ministry of Health and Social Security, the Public Health Institute of Iceland, nursery schools, schools, canteens in private and public operations and organisations, The Federation of Icelandic Industries, NGOs and private sports clubs in Iceland.

- $\quad$ For more information: www.althingi.is/altext/133/s/1149.html

Althingi, the Icelandic parliament, supports a four-year action plan that is intended to strengthen children's and young people's status in society.

${ }^{30}$ The Foodstuffs Act no. 93, 28 June 1995 
The Action Plan is based on the UN Convention on the Rights of the Child. In connection with the Action Plan, a committee has been appointed comprised of members from the Ministry of Social Affairs, the Ministry of Health and Social Security, the Ministry of Justice and Ecclesiastical Affairs, the Ministry of Finance, and the Ministry of Education, Science and Culture.

- $\quad$ For more information, go to www.felagsmalaraduneyti.is/media/acrobatskjol/

TAL_um_adgerdaaatlun_vegna_barna_og_ungmenna.pdf

\subsection{State-initiated projects and information material}

\subsubsection{Everything Affects us - Especially Ourselves!}

The Public Health Institute of Iceland has prepared the campaign Everything Affects Us - Especially Ourselves in collaboration with more than 20 municipalities ${ }^{31}$. The purpose of this campaign is to improve the lifestyle of children and young people, and their families. Everything Affects Us - Especially Ourselves is Iceland's "Best Practice”. Sub-section 10.3 presents a more detailed description of the project.

\subsubsection{The Food and Physical Activity circles}

The food circle was revised with the new nutrition recommendations from 2005. This presents six groups of foods which are now the same size, but in which the amounts of foodstuffs vary. Water is positioned in the middle of the circle.

A new activity circle has also been drawn up which illustrates how to incorporate physical activity into everyday life.

- For more information, got to www.lydheilsustod.is/frettir/ naering-og-holdafar/nr/1246

\subsubsection{Educational material}

The Public Health Institute of Iceland collaborates with the school heath sector in preparing educational material for school nurses. This material is used in their work with the pupils, and newsletters are also sent to the parents. The title is $6 \mathrm{H}$ for Health: Healthy food (hollur matur), rest (hvild), happiness (hamingja), hygienje (hreinlæti), physical activity (hreyfing) and prevention of use of tobacco and alcohol (hugrekki). The

\footnotetext{
${ }^{31}$ Directorate of Health, Annus Medicus 2005 p. 18
} 
number 6 represents sexuality and health. The focus on the different areas depends on the children's age.

- $\quad$ For more information, go to www.heilsugaeslan.is/?PageID=1339.

\subsubsection{Ministry of Education, Science and Culture}

The Ministry of Education, Science and Culture has launched Sporty Iceland, the purpose of which is to promote physical activity and investigate how society can create a forum for a healthier lifestyle.

Children in compulsory schooling have two obligatory sports lessons and one swimming lesson per week. National recommendations and guidelines for physical activity in schools, and how society can create fora for healthier lifestyles, are currently being drawn up.

In addition, children have one obligatory domestic science lesson per week from 1st-4th grades and two lessons per week from 5th-8th grades.

\subsubsection{5 a day $^{32}$}

In 1996, The Public Health Institute of Iceland, The Icelandic Heart Association, The Icelandic Cancer Society, fruit and vegetable wholesalers, and supermarkets formed a partnership with the aim of promoting the intake of fruit and vegetables. The partnership develops and produces advertisements and educational material for nursery schools, schools, workplaces and supermarkets.

- $\quad$ For more information: www.publichealth.is

\subsubsection{Cycle to work $^{33}$}

In 2003, The National Olympic and Sports Association of Iceland entered a partnership with The Public Health Institute of Iceland, cycle clubs and The Icelandic National Broadcasting Service to promote active transport such as cycling and walking to work. The strengths of the partnership are effective use of available resources, working towards a common goal, and easy access to national media such as TV and radio.

- $\quad$ For more information: http://hjolad.isisport.is/template1.asp? PageID=1

- Contact: Jona Hildur Bjarnadottir, e-mail: jona@isisport.is

${ }^{32}$ Experiences of EU member states on public-private partnerships (PPPs) on initiatives to counteract obesity. Update June 2007, version 21 June 2007. National Institute for Public Health and the Environment, May 2007.

${ }^{33}$ Experiences of EU member states on public-private partnerships (PPPs) on initiatives to counteract obesity. Update June 2007, version 21 June 2007. National Institute for Public Health and the Environment, May 2007. 


\subsubsection{Walk to school}

Every year, October is International walk to school month. Iceland took part in this project for the first time in 2007. The goals of the project are to encourage physical activity and to increase awareness of the need for easy-to-walk routes in the local community. The project partners are the Ministry of Education, the Road Traffic Directorate, the National Parents Association, the National Olympic and Sports Association of Iceland and the National Commissioner of the Icelandic Police.

- $\quad$ For more information, go to www.gongumiskolann.is

\subsubsection{Recommendations and guidelines}

In 2005, the Public Health Institute of Iceland published nutrition recommendations. These include recommendations for foodstuffs, nutrition and physical activity. The recommendations are based on the Nordic Nutrition recommendations 2004, the latest research within nutrition, and knowledge on the eating habits of the Icelandic population. In 2006, the recommendations were published as a brochure.

- $\quad$ For more information, go to www.lydheilsustod.is/media/manneldi/utgefid//mataraedi-lowres.pdf

The Public Health Institute of Iceland is responsible for revising and developing the recommendations for physical activity which were published at the end of 2007.

The recommendations for infant nutrition have been drawn up by the Public Health Institute of Iceland and the Centre for Child Health Services. These recommendations are used in connection with health studies of infants and toddlers. Their purpose is to:

- encourage full breastfeeding until 4-6 months of age

- guide parents at changeover to solids.

- draw special attention to iron and vitamin D deficiency.

In 2003, guidelines were drawn up for canteens in schools and nursery schools by the Public Health Institute of Iceland, which have been compiled with reference to official recommendations relating to the composition of diet and nutrition. It also deals with how to compose a menu, storage of food, special diets, hygiene and purchasing. In connection with the guidelines, a plate model was used to demonstrate how to compose a healthy meal. These recommendations are used by employees in school canteens. The recommendations include hot meals for the pupils on most weekdays. Most Icelandic municipalities now offer lunch in schools, which in most cases, is subsidised by the municipalities. 
- $\quad$ For more information, go to

www.lydheilsustod.is/media/manneldi/fraedsla/

Handrit_loka_litlarmyndir_vidbot_net_2utg.pdf

In 2005, in connection with the Everything Affects Us - Especially Ourselves! campaign, guidelines were also drawn up for kitchens in nursery schools by the Public Health Institute of Iceland. Generally, lunch and snacks are provided in nursery schools and follow the same criteria as those emphasised in the handbook for the school canteens.

- $\quad$ For more information, go to www.lydheilsustod.is/media/manneldi/fraedsla/ leikskolamappa_loka021005.pdf

The Public Health Institute of Iceland is currently compiling a handbook for schools containing guidelines on how physical activity can be incorporated into the school day. The handbook demonstrates that it is possible to create more activity-friendly environments in schools.

\subsubsection{Monitoring}

Iceland focuses on child health examinations, health education and health-promotion in schools targeting lifestyle factors. The examinations are conducted by nurses and general practitioners. The children are followed up regularly until they leave compulsory schooling (around the age of 15), at which height and weight are measured every third year (6, 9, 12 and 15 years).

The Public Health Institute of Iceland has together with the involved parties collected data on the population's nutritional status and physical activity status:

- In 2006, the health behaviour of school children (HBSC) was examined for 11, 13 and 15-year olds.

- In 1990 and 2002, the Icelandic People’s Dietary Habits were examined (15-80-year olds).

- In 1992 and 1993, the Icelandic Children’s Dietary Habits were examined (10, 12 and 14-year olds).

- Questionnaires were distributed to the school principals in compulsory schooling and nursery schools in January 2005, 2007 and 2010, in which the schools' environments and availability of food, drink and physical activity were surveyed.

- The Unit for Nutrition Research, and the Landspitali University Hospital \& Department of Food Science and Nutrition at the 
University of Iceland have collected data on children and young people's dietary habits. In Iceland, infant nutrition was examined in 1995 and 2006, the dietary intake of 2-year olds in 2000, of 6-year olds in 2002, and of 9 and 15-year olds in 2002-03.

\subsection{Best Practice}

\subsubsection{Everything Affects us - Especially Ourselves!}

In the autumn of 2005, the project Everything Affects us - Especially Ourselves! was launched. The first part concludes in 2007 and the second in 2010.

The project is based on a multifactorial, population-based, primary prevention strategy. It is intended to increase the population's awareness of factors relevant to promoting health. At the same time, conditions for promoting health are to be improved. The target groups are children and young people and their families in the participating municipalities. The project will:

- enable dissemination of knowledge and changed attitudes so that young people and parents raise their levels of physical activity and acquire healthier dietary habits

- give local communities advice on school and nursery school canteens

- distribute a checklist that municipalities and involved parties can use to evaluate the status of physical activity, nutrition and environment.

The participating municipalities will draw up their own policies and action plans for promotion of physical activity and nutrition in accordance with their actual needs and circumstances. The benefits expected from the project are:

- Improved municipal policies: The municipalities formulate and approve a policy that focuses on increased physical activity and better diet as well as funding local projects.

- Changes in attitude and knowledge: changes in the pupils' and parents' attitudes to physical activity and better diet in relation to children can be evaluated.

- Healthier environments in schools: More sports lessons, healthier food, more physical activity before, during and after school hours.

- Improved lifestyle: Examples of improved lifestyle are more physical activity, healthier diet, less inactivity and more time for family life.

- Reduction in the risk factors that include low fruit and vegetable intake, and physical inactivity.

- Long-term goal: Increased quality of life and improved health. 
The evaluation work is performed by the Public Health Institute of Iceland. A baseline evaluation was conducted in 2005 which will be followed up in 2007 and 2010. The factors assessed include:

- the environments of the schools and children

- children's attitudes, skills and conduct

- parents' attitudes

- measurement of children's height and weight taken by the school health centres

Most municipalities participating in the project have prepared goals and action plans with primary emphasis on better dietary habits and more exercise. The initiatives vary between municipalities, but the individual municipalities should base them on the framework of Everything Affects us - Especially Ourselves!

- For more information, go to http://lydheilsustodvefur.eplica.is/media/ allthefurahrif/Public_Health.pdf

- Contact: Jórlaug Heimsidóttir, The Public Health Institute of Iceland. E-mail: jorlaug@publichealth.is 



\section{Health promotion through labelling and marketing of foodstuffs}

The Swedish Consumers' Association has mapped commercials for unhealthy foods that target children and young people in comics/direct advertising, on the internet and on $\mathrm{TV}^{34}$. Half of all commercials on child internet sites were for unhealthy foodstuffs. $26 \%$ of adverts in children's comics and direct advertising was for unhealthy food, and $20 \%$ of food commercials on TV was for unhealthy food.

Labelling of healthy and unhealthy foodstuffs as a means of improving consumer information has been discussed in some Nordic countries in recent years. Sweden, Denmark and Finland have established labelling schemes (more about these below). Both this area and marketing have been targeted in the Nordic Action plan on better health and quality of life through food and physical activity as areas that are particularly amenable to closer Nordic co-operation.

\subsection{The goals of the Nordic Council of Ministers}

The Nordic Action plan for better health and quality of life through food and physical activity stipulates:

- Marketing of unhealthy foodstuffs affect children and young people’s consumption and attitudes to healthy food negatively and should therefore be restricted. The Nordic countries will hold the EU commission to the ultimatum it gave to the industry to stop marketing unhealthy food directed at children, and will jointly demand EU regulation if the current conduct does not change via self-regulation.

- Labelling of foodstuffs will make it easier for the consumer to choose healthy products and make informed food choices. Studies have shown that the consumer requests easily understood labelling with simplified information on the nutrition declaration.

- The Nordic countries will collaborate on promoting the Nordic proposals for better nutrition declarations in connection with the upcoming revision of the EU nutrition declaration directive, and will

34 „Handlingsplan for bedre kosthold i befolkningen (2007-2011) - Oppskrift for et sunnere kosthold“., s. 32 (Action plan for a better diet in the population (2007-2011) - Recipe for a healthier diet, p 32) 
strive for obligatory nutrition declarations. The possibilities of harmonising the criteria behind differing nutrition labelling schemes used in the Nordic countries will be investigated further.

\subsection{Joint Nordic initiatives}

- Conference on marketing of food and drink directed at children and the consequences for children's food habits. NMR was involved in funding a WHO expert meeting on this subject in 2006.

- In 2007, the Nordic Council of Ministers published a report entitled Söt reklam og feta ungar (Sweet advertising and fat children) which mapped the scope and form of adverts for unhealthy foodstuffs targeting children in Sweden. One of the aims of the report was to find methods to conduct comparative studies and measurements in this area in the Nordic region.

- The subject of marketing of unhealthy foodstuffs targeted at children was discussed at the Nordic Ministers' summer meeting in June 2007. At the meeting, the Nordic Ministers passed a joint resolution that encouraged the Nordic countries to draw up a common, voluntary code of ethics to restrict marketing of unhealthy foodstuffs directed at children and young people. The Ministers Council similarly encouraged the Nordic countries to strengthen their co-operation and experience exchange within mapping of this area, for example.

- In August 2007, a meeting was held by high-level Nordic Senior Officials with the purpose of sounding out the possibilities of establishing joint Nordic voluntary nutrition labelling, based on the existing and proposed nutrition labelling schemes in the Nordic regions.

- In September 2007, a seminar funded by the Nordic Council of Ministers was held called Harmonizing Criteria behind the Signpostlabelling Schemes in the Nordic Countries. Here representatives for the relevant authorities discussed the possibilities of harmonizing Nordic criteria. The results of this work will be incorporated in the work to investigate the possibilities of a joint Nordic nutrition label.

\subsection{Danish initiatives on labelling and marketing}

\subsubsection{Labelling}

In April 2007, Denmark launched a new voluntary labelling symbol "The Eat Label”, which in principle includes all foodstuffs. The signpostlabelling scheme divides all foodstuffs into three categories - eat most, less or least - based on an assessment of the fat, saturated fat and sugar 
content and, where relevant, dietary fibre, salt and content of fruit and vegetables. In accordance with EU labelling regulations, the scheme is voluntary for manufacturers.

The label was launched on a new website www.spismest.dk, where consumers could test specific products. They could also find examples of product tests in which various foodstuff categories had been tested with specification of whether a given product belonged to the eat most, less or least category. The hope is that this information on the internet can guide consumers to eat less fat, sugar and salt, and more dietary fibre, fruit and vegetables.

Unfortunately, the label has received considerable opposition from wholesalers and the industry. This extensive criticism, particularly of the scheme's possibilities to label the less nutritionally-quality products, has resulted in highly limited voluntary labelling - this also applies to the category "Eat Most“.

In recognition of the fact that it will not be possible to promote use of signpost labelling without the support of the foodstuff industry and retailers, the Danish Parliament has requested that the Minister of Family and Consumer Affairs contact Nordic colleagues with the purpose of discussing the establishment of a joint Nordic nutrition labelling scheme that is only perceived as positive labelling (such as the EATmost logo or the keyhole symbol).

Denmark sees several advantages of a joint Nordic nutrition label:

A joint Nordic label will promote the use of the label by the industry and the retailers in all Nordic countries. The Nordic retailers and foodstuffs industry operate to a large extent across the Nordic country boundaries. The industry and retailers can therefore see greater benefit in using the label if it can be used in marketing in several Nordic countries.

A joint Nordic label will also ensure that the Nordic countries have a clearly defined position with respect to the coming years' discussions and negotiations at EU level on nutrition labelling.

\subsubsection{Marketing}

It is stipulated in the Marketing Act ${ }^{35}$, that marketing that targets children and young people must be designed taking into particular consideration the child's and young person's natural trust and lack of experience and critical sense, which means that they are easily influenced and manipulated.

In the Consumer Ombudsman's guidelines from July 2006 Børn, unge og markedsføring (Children, Young People and Marketing), which covers marketing in schools and day care facilities, it was emphasised that companies that market unhealthy foodstuffs such as sweets, crisps, sweet soft drinks and similar, should exercise a particular responsibility when mar-

${ }^{35}$ Act no. 1389 of 21/12/2005 on marketing, § 8 
keting such products towards children and young people. Choice of media, and design and content of the advert, must be considered carefully with respect to children and young people. An advert for unhealthy products that is directed at children and young people must not convey an impression that use of the product is healthy or can give success. Neither must the advert encourage nor inspire to excessive consumption of unhealthy foodstuffs nor undermine healthy dietary habits and lifestyles.

In order to acquire the optimal scientific evidence for initiatives, the Minister of Consumer and Family Affairs in Denmark has also ordered a study to map the extent of marketing directed at children and to investigate where children are met with marketing of unhealthy foodstuffs. The study will establish a good foundation from which to assess the initiatives that will be needed. It will also be possible to use the study as a zero point, giving the opportunity at a later date to study status and, if necessary, to evaluate whether the initiative has been sufficiently effective.

Individual interest organisations/industrial unions in Denmark have established a code of ethics that include marketing to children. Work is also ongoing to establish a forum for Co-regulation of the Marketing of Foodstuffs targeting Children ${ }^{36}$.

In March 2007, the Danish supermarkets launched a joint scheme in the battle against obesity. This stipulates that supermarkets must avoid advertising unhealthy foodstuffs (sweets, soft drinks, crisps, etc.) in media directed at children, defined in detail as TV commercials for children, children's comics, children's websites and SMS adverts directed at children.

\subsection{Norwegian initiatives on labelling and marketing}

\subsubsection{Labelling}

Some of the supermarket industry has introduced the Swedish keyhole symbol, c.f. below.

On 22 January 2007, the government submitted "Handlingsplan for bedre kosthold i befolkningen (2007-2011) - Oppskrift for et sunnere kosthold", s. 32 (Action plan for a better diet in the population (20072011) - Recipe for a healthier diet) The Action Plan contains 73 initiatives distributed between 10 investment areas. The plan is backed by 12 departments.

As sub-goals, the Action Plan lists:

- Facilitating consumers' choice of foodstuffs in a good nutritional context.

\footnotetext{
${ }^{36}$ Co-regulation is a combination of state and private regulation in which a state authority collaborates with an industry, company or organisation on an ethical code.
} 
- Improving the choice of and exposure to foodstuffs with good nutritional composition.

- Reducing exposure to foodstuffs that contribute to a diet that is not health- promoting, in particular for children and young people.

As a follow up to the sub-goals, consumption of fruit and vegetables will be promoted by stimulating increased access to good quality raw materials. During the duration of the Action Plan, there must be a review of the use of the policy instrument in the production chain to evaluate how it supports the goals of the consumer, food and nutrition policies. The Nordic Council of Ministers' project Ny nordisk mad (New Nordic Food) will be relevant in this connection.

Work will also concentrate on better labelling of foodstuffs including improved nutrition declarations. Norwegian authorities will work on obligatory/legislated nutrition declarations on foodstuffs as input to the revision of the EU labelling directive. Labelling of the added sugar content has also been proposed as part of the obligatory labelling.

Furthermore, introduction of a voluntary, public scheme for nutrition labelling/symbol marking is planned to facilitate composing a healthy diet. Reference is made in the Action plan to the ongoing Nordic efforts within the possibilities of joint Nordic criteria for so-called nutrition labelling or symbol marking.

\subsubsection{Marketing}

The current Marketing Act does not contain provisions linked to marketing directed at children and young people. There is therefore no ban on directing adverts at one target group in particular. The Consumer Ombusdman and the Advertising Standards Board, which together are responsible for monitoring the Marketing Act, do however interpret the general principles more strictly when the target group for marketing is children and young adults. The Marketing Act is under revision.

Radio and TV commercials in Norway are regulated by the Broadcasting Act. Commercials cannot be sent in connection with children's programmes, and commercials cannot specifically target children. This ban applies to all types of products, including foodstuffs.

The Norwegian government's Handlingsplan for bedre kosthold $i$ befolkningen (2007-2011) (Action Plan for better diet in the population) deals with marketing of foodstuffs and drinks directed at children. Under the programme Sunn mat $i$ et mangfoldig marked (Healthy food in a diverse market) one of the initiatives is to evaluate the introduction of restrictions on marketing of unhealthy foodstuffs directed at children and young people. The suitability of legislation as an instrument to restrict this form of marketing will be investigated. The Action Plan stipulates that the same investigation should also consider whether there is a need 
for legislative changes, which law such a change should be pursuant to, how this resolution could be formulated, and who should be responsible for enforcing and monitoring, etc., and that the initiatives must be evaluated compared to the results of self-regulation.

Sections of the Norwegian foodstuff industry have committed to selfregulation because they have signed Retningslinjer for markedsføring av mat og drikke rettet mot barn og unge (Guidelines for marketing of foodstuffs and drinks directed at children and young people) which was launched in September 2007. The initiative-taker was the Norwegian Consumer Council. They have drawn up the guidelines in collaboration with the foodstuffs industry. The aim of the guidelines is to contribute to good and responsible marketing practice and they stipulate that suppliers of energy-dense and nutritionally-poor foodstuffs should not make commercials directed at children. The Consumer Council will follow up the efforts to ensure compliance with the intentions in the guidelines.

Norway has assumed responsibility to lead a European network on marketing of foodstuffs and drinks to children. This is a follow up to a resolution at the World Health Assembly in May 2007; recommendations in a European Charter on overweight that was signed by the Health Ministers at the WHO Minister Conference in Istanbul in November 2006; and recommendations in the European Action Plan for Food and Nutrition Policy in Who Region Europe (2007-2012) which was passed in September 2007, that WHO shall draw up guidelines for marketing of foodstuffs and drinks to children. So far, nine member countries in WHO Region Europe have notified their interest to participate in the network. The first meeting of the network takes place in Oslo in mid-January 2008.

\subsection{Swedish initiatives on labelling and marketing}

\subsubsection{Labelling}

The National Food Administration symbol the "keyhole" is intended to help consumers find healthy alternatives ${ }^{37}$. Keyhole-labelled foodstuffs contain less sugar and salt but more beneficial fat, and more dietary fibre than other foodstuffs of the same type. In order to be labelled with the keyhole symbol, foodstuffs must meet certain criteria that are decided by the National food Administration. The criteria - determining how much fat, fibre, sugar and salt a keyhole-labelled foodstuff must contain - are based on the Nordic nutrition recommendations that are founded in scientific research

The keyhole is a voluntary label. The foodstuff industries themselves are responsible for ensuring that keyhole symbol foods meet the regulations of the National Food Administration. Labelling control is conducted

\footnotetext{
${ }^{37}$ Website of the National Food Administration www.slv.se
} 
in the first instance by the municipal environmental and healthcare boards.

\subsubsection{Marketing}

The Consumers council/Consumer Ombusdman (CO) has come to several agreements with the industry on how marketing directed at children should be designed, for example Christmas gift adverts and school photos. In accordance with the Radio and TV Act, no commercials of any sort can be sent immediately before or after a children's programme. Neither can children's programmes be interrupted by commercials. The Investigation Board for radio and TV monitor that these regulations are complied with.

TV commercials must not be designed to attract the attention of children younger than 12 years of age. TV commercials that contravene this ban will thus be considered to be illegal. Compliance with this resolution is monitored by CO. When evaluating these, all significant factors are included, such as what the commercial is for, the design of the commercial, and in which context the commercial takes place. The regulations apply to TV 4. Because TV 3 and Kanal 5 do not transmit from Sweden, they are not covered by this ban on commercials directed at children.

As mentioned above, the National Food Administration and the Swedish Institute of Public Health drew up a draft proposal for an action plan for good dietary habits and increased physical activity in the population in February $2005^{38}$. Among the 79 proposals for initiatives, there is one proposal that "the criteria for restricting marketing of food directed at children must be tested, including with respect to current legislation”.

\subsection{Finnish initiatives on labelling and marketing}

\subsubsection{Labelling}

The heart symbol was launched in 2000, and is administrated by the Finnish Heart Association and the Finnish Cancer Organisation. This symbol informs the consumer that the heart-labelled product is a better choice in that product group with respect to fat and sodium (salt). The purpose of the heart symbol is to promote the health of the population. At the present time, six product groups are entitled to use the heart symbol. Those products for which fat and salt are not a problem (such as fruit and vegetables) are not included in the scheme.

\footnotetext{
${ }^{38}$ Sammanfatning av regeringsuppdrag Goda matvanor och ökad fysisk aktivitet - underlag til handlingsplan, Statens folkhälsoinstitut www.fhi.se (Summary of the Government's remit Good food habits and increased physical activity - documentation for an action plan, The Swedish National Board of Public Health).
} 


\subsection{Icelandic initiatives on labelling and marketing}

There are no specific labelling schemes in Iceland at present, but these have been discussed and many parties are positive. The current Food Act stipulates several provisions relating to marketing, misrepresentation and labelling that apply to both adults and children.

\subsubsection{Marketing}

Iceland has a Marketing Act (no. 44/2005), that allows intervention in misleading commercials including misleading commercials for foodstuffs. It is stipulated in the Broadcasting Act (no. 53/2000), that commercials are banned in programmes for children both on radio and TV.

The consumer ombudsman and children's ombudsman in Iceland have initiated work to draw up an agreement with the industry on marketing that is directed at children and young people. They have also held a seminar with the Parents' Association Hjem og skole (Home and School) about children and adverts. 


\section{Visions}

- This catalogue is designed to facilitate the compilation of additional catalogues that cover discreet topics in the future.

- Now that a comprehensive project on joint monitoring has been initiated, a patent subject for the next catalogue would be evaluation of, and visions for, joint monitoring in the Nordic region.

- The Nordic co-operation on better health can be advantageously compared to equivalent activities under WHO, EU and OECD - work in this area should therefore continue and be developed. This will enable greater influence, back-up and improved congruence if the efforts are correlated with initiatives that are implemented in a wider context.

- A database that provides an overview of the projects' diversity and content would be a good tool and an excellent source of inspiration. This would enable easy and clear searching for individual projects and an overview of projects within given areas. Work should promote joint European data overviews (under WHO/EU) in order to facilitate wider use of Best Practices. 



\section{Appendix}

Table overview of each country's initiatives listed by topic 



\begin{tabular}{|c|c|c|c|c|c|c|c|c|c|c|c|c|c|c|c|}
\hline 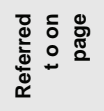 & 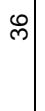 & లె & $\tilde{m}$ & ల్ల & ले & m & 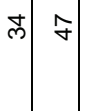 & คి & ८) & 요 & \begin{tabular}{l|l}
8 & 8
\end{tabular} & $\tilde{\sigma}$ & $\stackrel{\circ}{N}$ & $\stackrel{\llcorner}{N}$ & $\stackrel{\sim}{N}$ \\
\hline 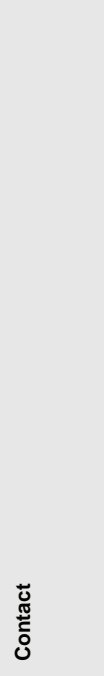 & 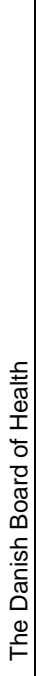 & 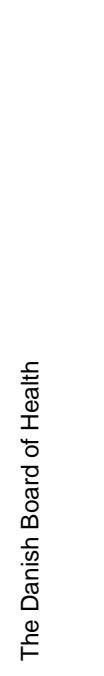 & 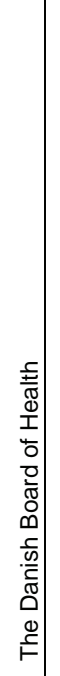 & 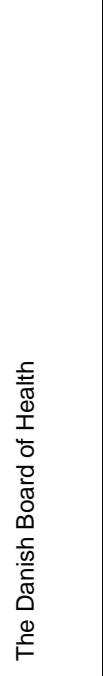 & 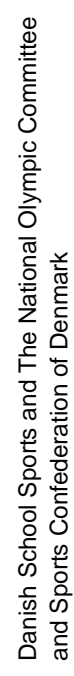 & 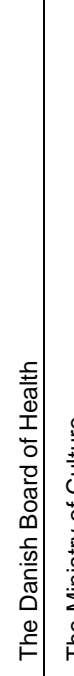 & 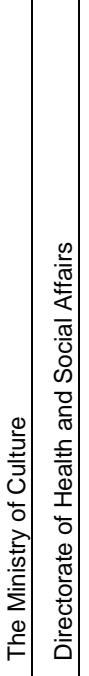 & 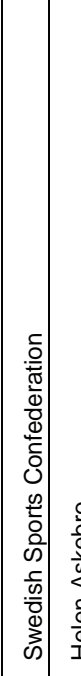 & 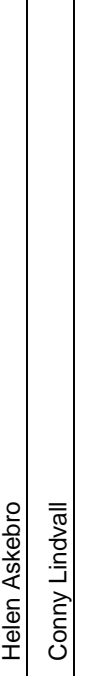 & 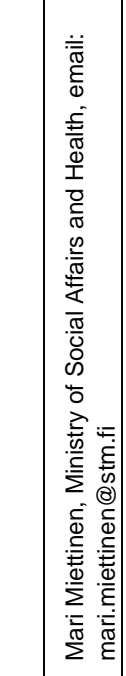 & 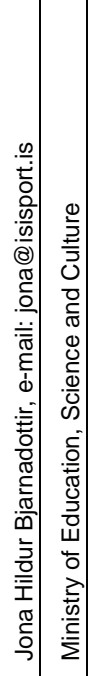 & 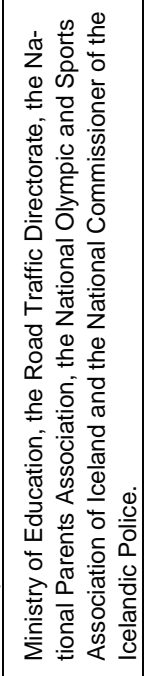 & & & \\
\hline 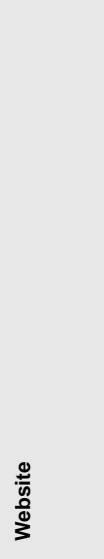 & 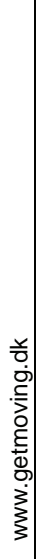 & 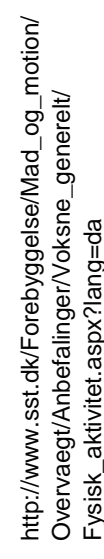 & 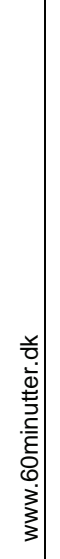 & 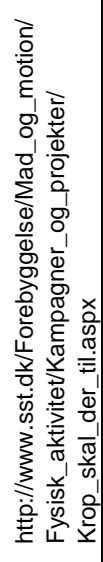 & 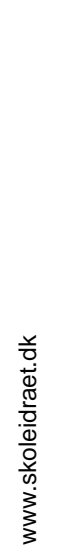 & 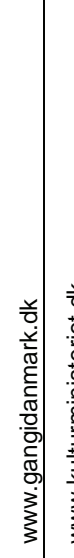 & 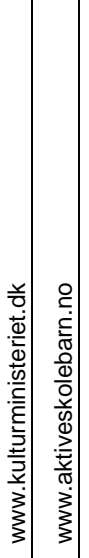 & $\begin{array}{lll} & \\
& \\
0\end{array}$ & 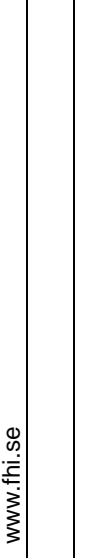 & & 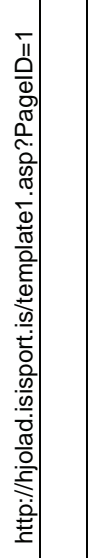 & 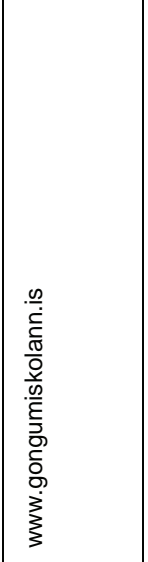 & & & \\
\hline 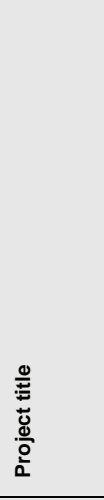 & & 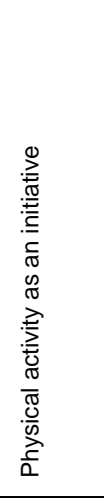 & 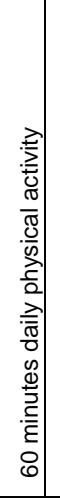 & 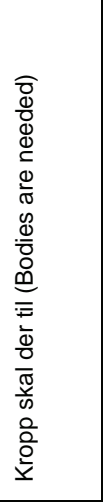 & 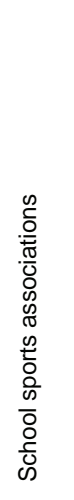 & 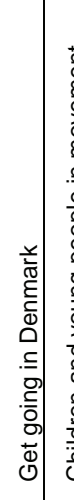 & 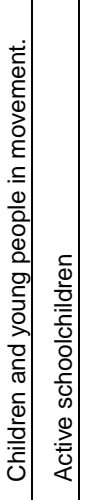 & 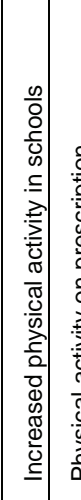 & 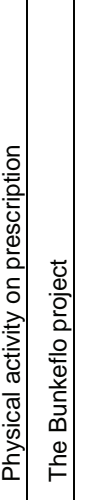 & 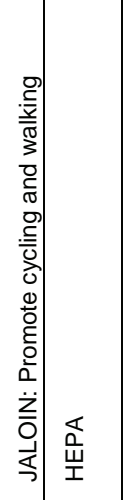 & 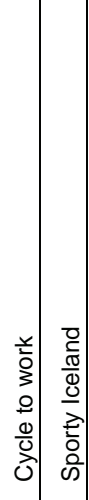 & 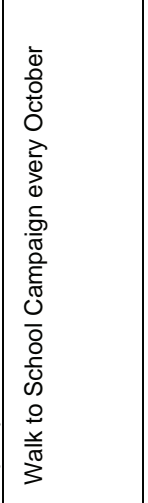 & 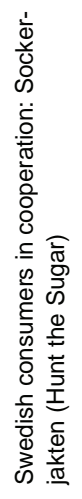 & 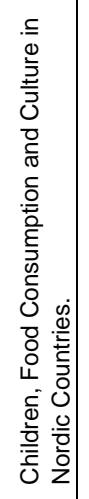 & 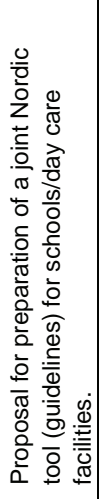 \\
\hline $\begin{array}{l}\text { 离 } \\
\stackrel{5}{5}\end{array}$ & 号 & & & & & & 2 & 岕 & & ॅ & $\underline{\Omega}$ & & $\sum_{z}^{\frac{N}{z}}$ & & \\
\hline 言 & 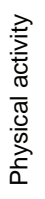 & & & & & & & & & & & & 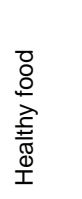 & & \\
\hline
\end{tabular}




\begin{tabular}{|c|c|c|c|c|c|c|c|c|c|c|c|c|c|c|c|}
\hline 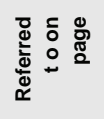 & $\hat{m}$ & $\vec{m}$ & $\widetilde{m}$ & $m$ & 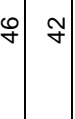 & $\vec{\gamma}$ & $\overrightarrow{7}$ & \% & 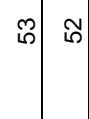 & 䓃 & i̊ & - & ঙે & ஓ & $\vec{m}$ \\
\hline 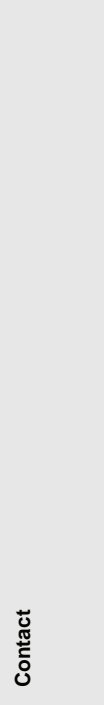 & & 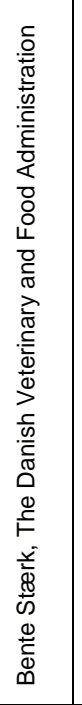 & 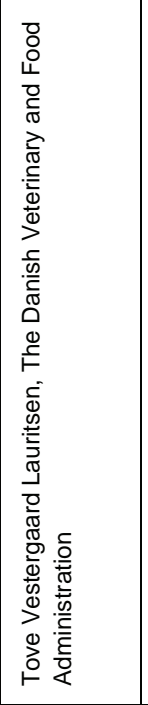 & 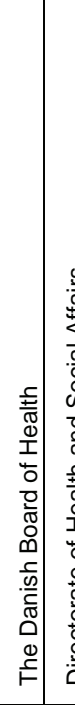 & 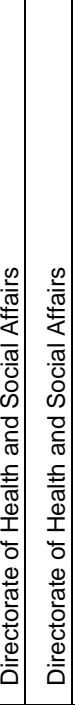 & 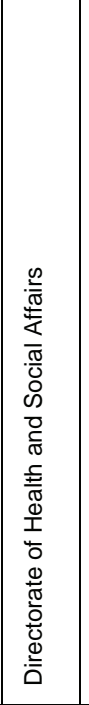 & 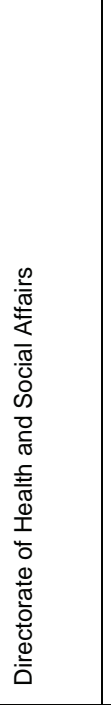 & 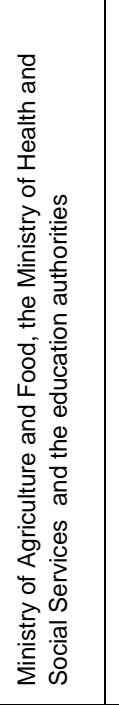 & 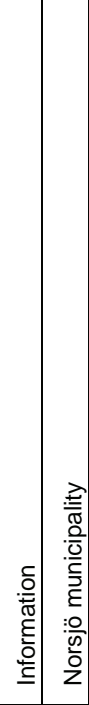 & 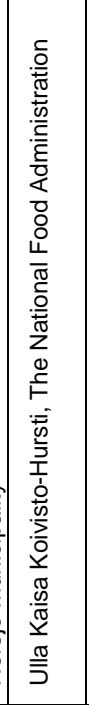 & 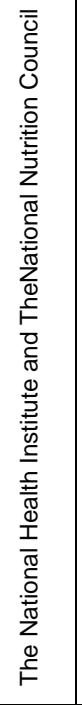 & & 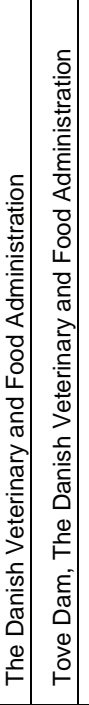 & 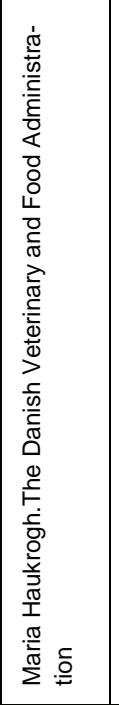 & 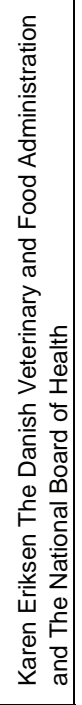 \\
\hline 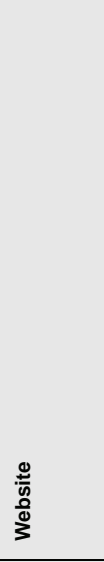 & 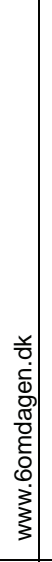 & & 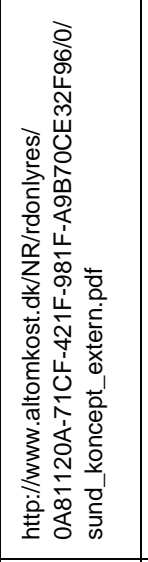 & & 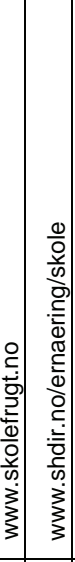 & 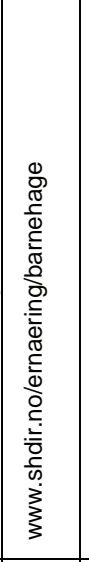 & 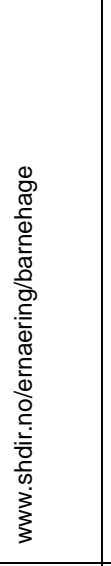 & 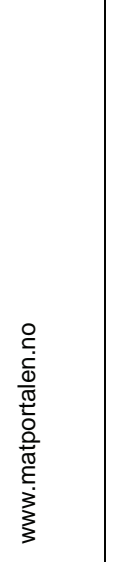 & 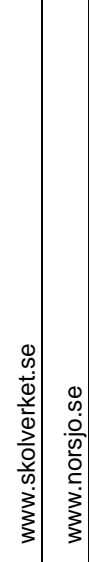 & 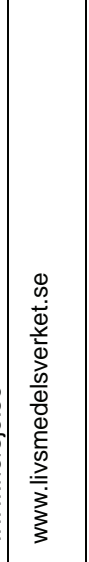 & 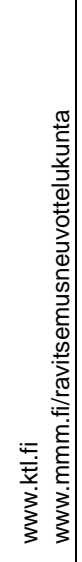 & 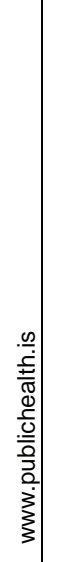 & \begin{tabular}{|c|c|} 
& \\
& \\
& \\
0
\end{tabular} & 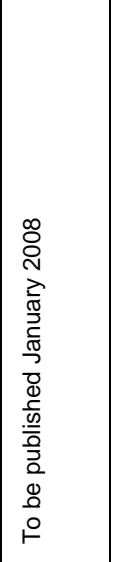 & 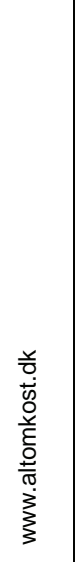 \\
\hline 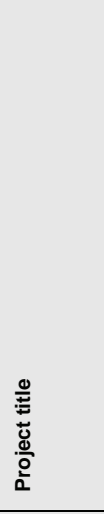 & & 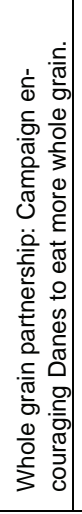 & 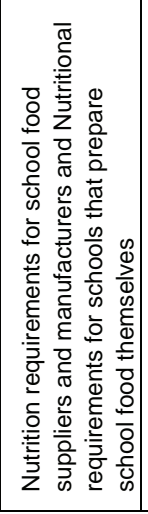 & 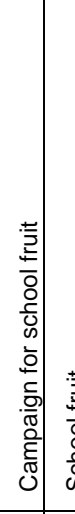 & 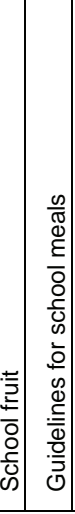 & 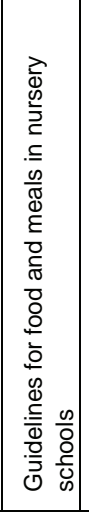 & 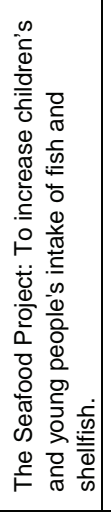 & 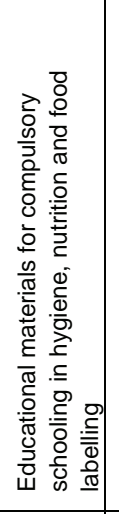 & 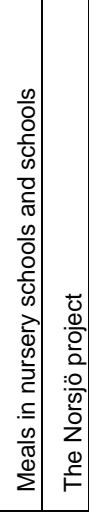 & 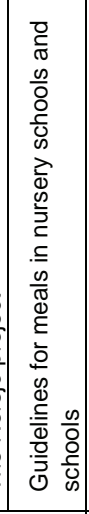 & 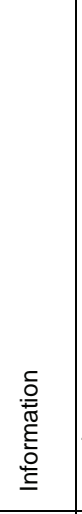 & & 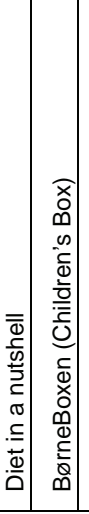 & 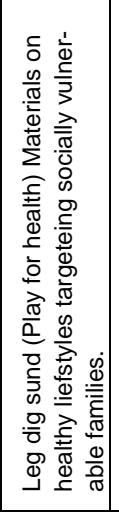 & 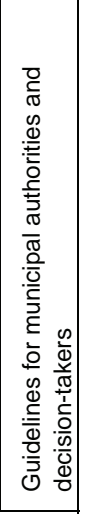 \\
\hline $\begin{array}{l}\text { 离 } \\
\text { sँ }\end{array}$ & 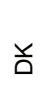 & & & & $\frac{0}{z}$ & & & & 岕 & & 匹 & $\underline{\Omega}$ & \multicolumn{3}{|c|}{ 号 } \\
\hline : & & & & & & & & & & & & & \multicolumn{3}{|c|}{ 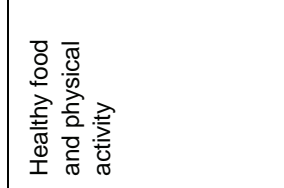 } \\
\hline
\end{tabular}




\begin{tabular}{|c|c|c|c|c|c|c|c|c|c|c|c|c|c|c|}
\hline 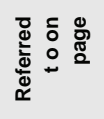 & $\vec{m}$ & $m$ & $\stackrel{\sim}{N}$ & ల్ల & $\stackrel{\sim}{\stackrel{9}{9}}$ & ᄂ? & 7 & ธิ & 毡 & : & $\tilde{\sigma}$ & 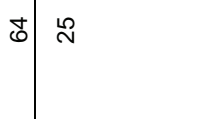 & $\stackrel{\circ}{N}$ & ซึ \\
\hline 芯 & 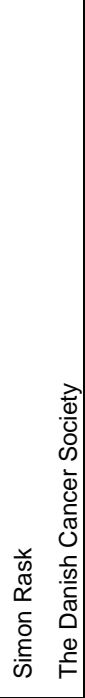 & 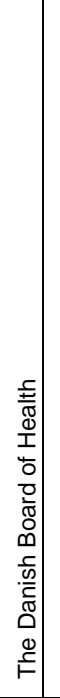 & 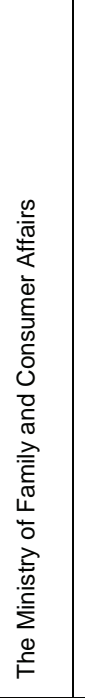 & 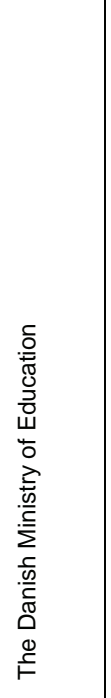 & & 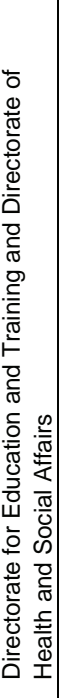 & 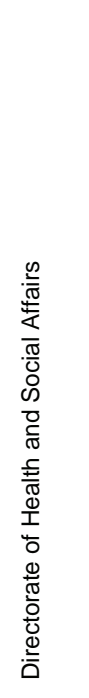 & 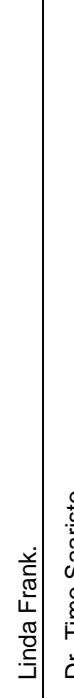 & & 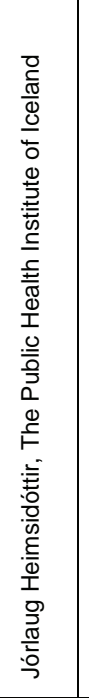 & 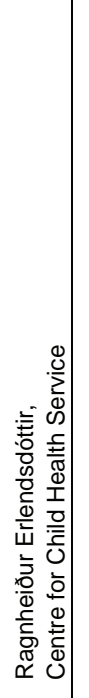 & 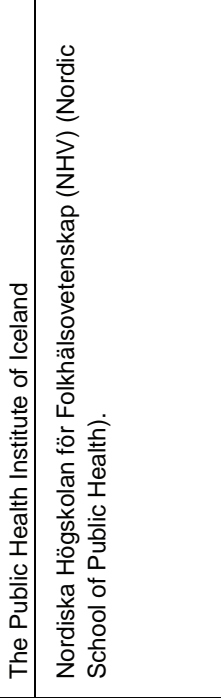 & & 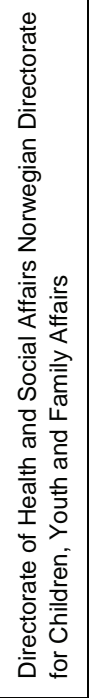 \\
\hline 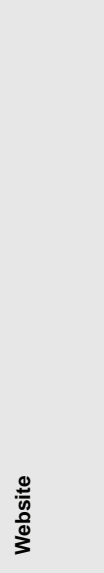 & 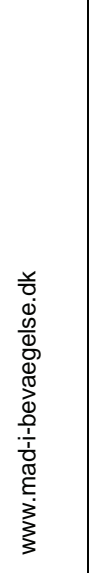 & 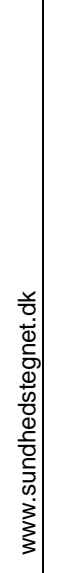 & 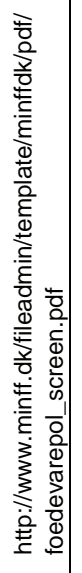 & 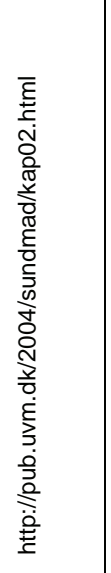 & 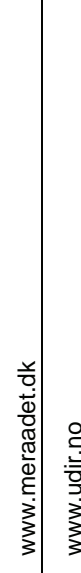 & مُ & 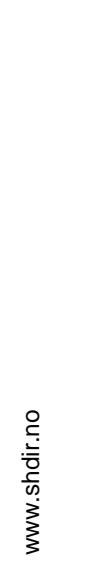 & 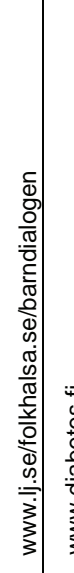 & 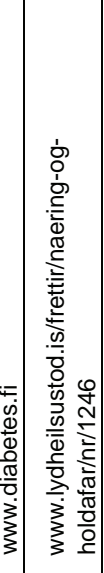 & & 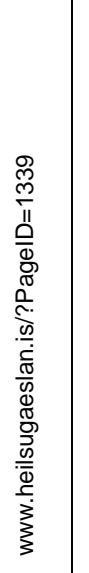 & 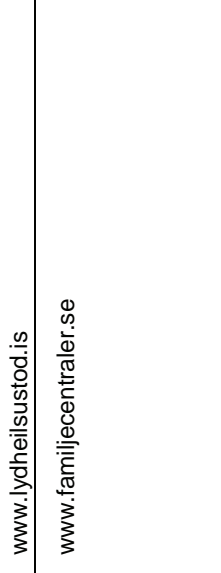 & & 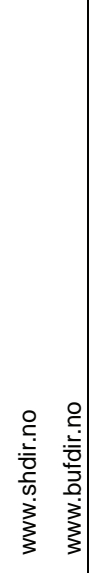 \\
\hline 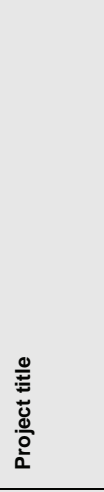 & 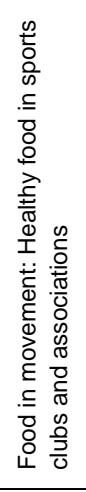 & & 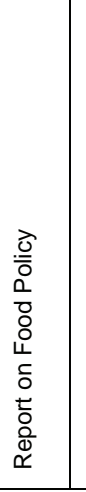 & 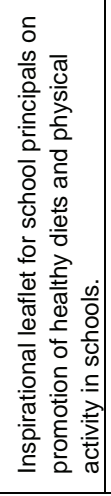 & 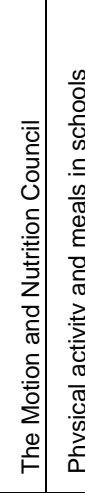 & 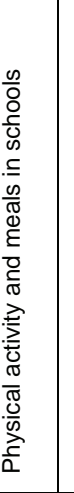 & 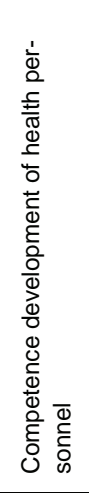 & 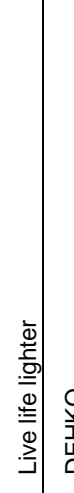 & 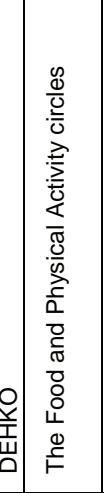 & 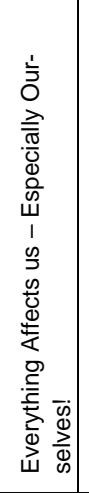 & 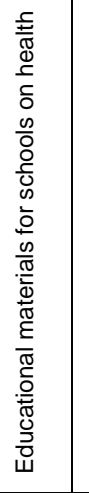 & 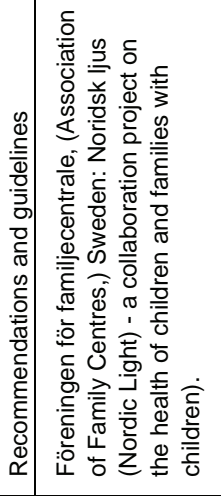 & 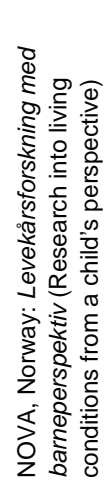 & 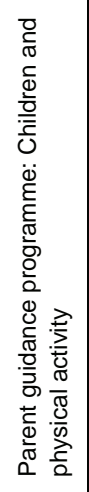 \\
\hline $\begin{array}{l}\frac{\bar{g}}{\tilde{s}} \\
\bar{\Sigma}\end{array}$ & & & & & & & 2 & $\ddot{\omega}$ & \begin{tabular}{l|l}
$\bar{\amalg}$ & $\varrho$
\end{tabular} & & & $\sum_{\Sigma}^{\frac{N}{L}}$ & & $\stackrel{\circ}{z}$ \\
\hline 产 & & & & & & & & & & & & 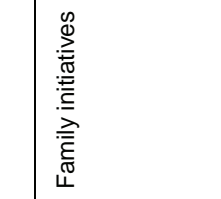 & & \\
\hline
\end{tabular}




\begin{tabular}{|c|c|c|c|c|c|c|c|c|c|c|c|}
\hline 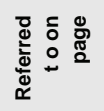 & $\stackrel{\sim}{N}$ & 아 & เે & $F$ & q & $\stackrel{\infty}{\circ}$ & ĥ & \begin{tabular}{l|ll}
$\stackrel{0}{0}$ & $\stackrel{0}{0}$
\end{tabular} & $\stackrel{\llcorner}{\sim}$ & $\stackrel{\circ}{\sim}$ & $\stackrel{\circ}{\sim}$ \\
\hline 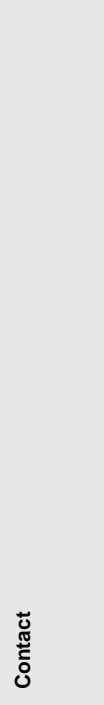 & & & 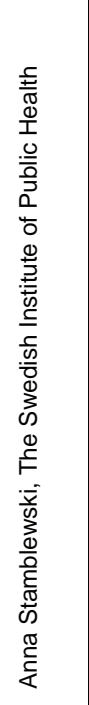 & 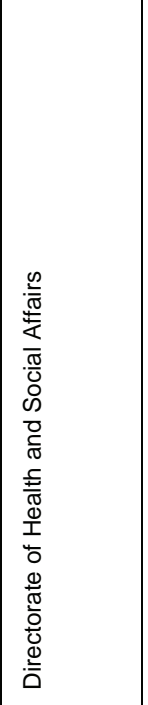 & 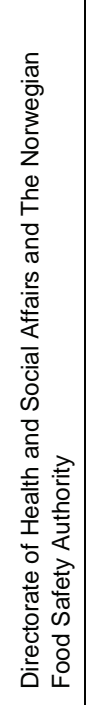 & 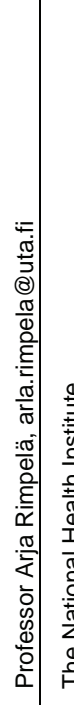 & 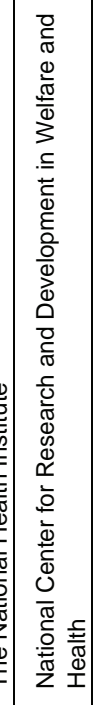 & 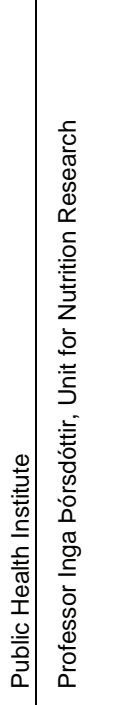 & & & \\
\hline 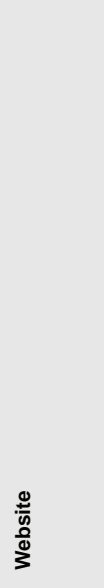 & & 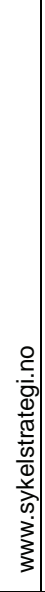 & 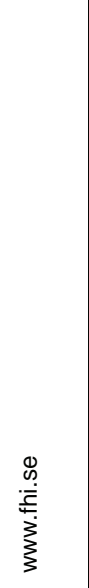 & 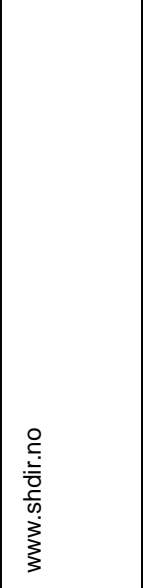 & 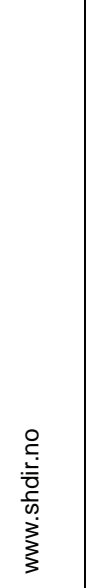 & & 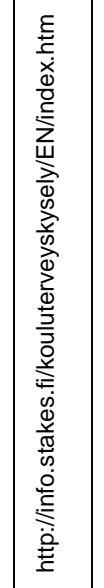 & & & & \\
\hline 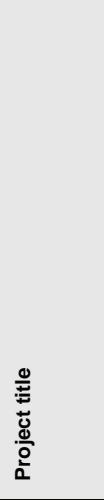 & 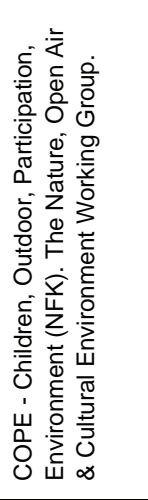 & 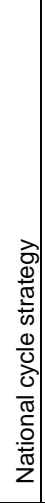 & 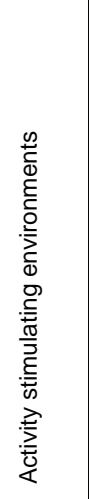 & 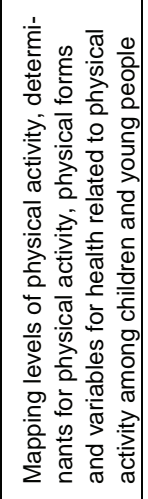 & 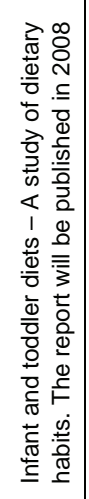 & 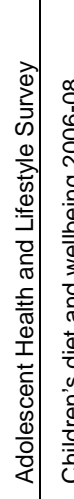 & 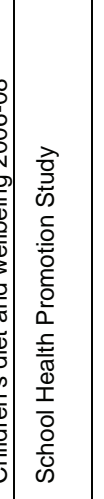 & 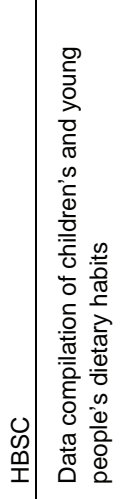 & 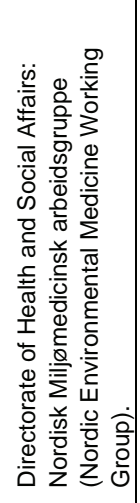 & 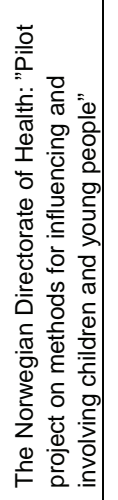 & 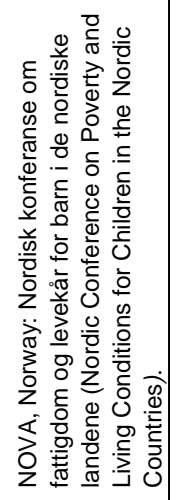 \\
\hline $\begin{array}{l}\frac{\grave{\mathrm{d}}}{\mathrm{g}} \\
\end{array}$ & $\sum_{\sum}^{\frac{N}{z}}$ & $\stackrel{o}{2}$ & ஸे & $\frac{\rho}{2}$ & & ш & & $\underline{\Omega}$ & $\sum_{z}^{\alpha}$ & & \\
\hline 产 & 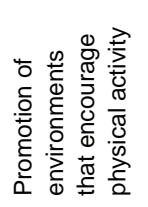 & & & 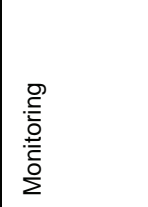 & & & & & 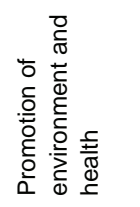 & & \\
\hline
\end{tabular}




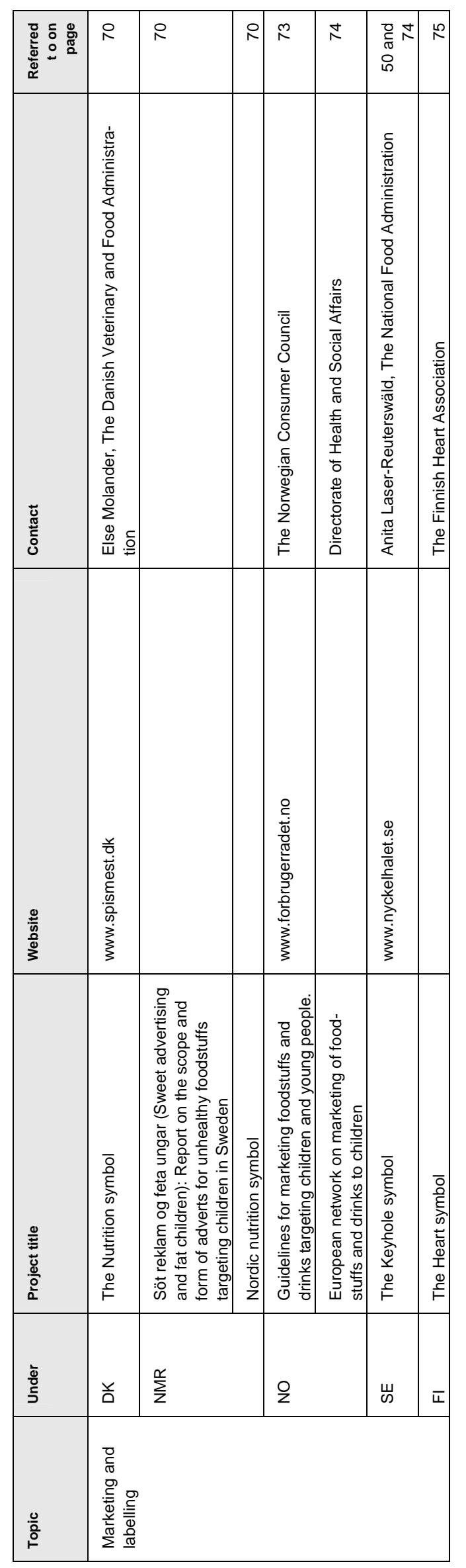


